\title{
Heuristics and Biases in Evaluations of Economic Inequality
}

Jonathan Bogard ( $\square$ jonathan.bogard@gmail.com )

UCLA https://orcid.org/0000-0002-2700-7427

\section{Colin West}

UCLA

\section{Craig Fox}

Anderson School of Management, UCLA

\section{Article}

Keywords: heuristics and biases, policy preferences, inequality, redistribution

Posted Date: February 9th, 2022

DOI: https://doi.org/10.21203/rs.3.rs-1278751/v1

License: (1) This work is licensed under a Creative Commons Attribution 4.0 International License. Read Full License 


\title{
Heuristics and Biases in Evaluations of Economic Inequality
}

\author{
Jonathan E. Bogard ${ }^{1}$, Colin West ${ }^{1}$, and Craig R. Fox ${ }^{1}$
}

${ }^{1}$ University of California, Los Angeles 


\begin{abstract}
How money ought to be distributed among different groups is a critical question influencing elections and policymaking. In eight pre-registered studies $(N=4,188)$ we show that people across the political spectrum are systematically biased when making judgments about economic inequality. We hypothesize that people reduce the complexity associated with such judgments by relying on a simplifying strategy in which they mainly focus on differences in wealth between the most salient groups, usually the richest versus poorest groups. This implies two biases. First, judgments about economic distributions are under-sensitive to differences in the size of identified population groups. This results in greater tolerance for inequality and lower support for redistributional policies when richer groups are composed of fewer individuals than poorer groups (e.g., comparing the richest 10\% versus the rest of the country). Second, judgments systematically underweight information about intermediate groups relative to the richest and poorest groups. This leads to a systematic neglect of the prosperity of the middle class. We show that these biases influence downstream policy support as strongly as differences in partisanship, and we conclude by proposing guidelines for presenting economic distributions in ways that are less susceptible to these biases.
\end{abstract}

Keywords: heuristics and biases, policy preferences, inequality, redistribution 
HEURISTICS AND BIASES IN EVALUATIONS OF ECONOMIC INEQUALITY

\section{Heuristics and Biases in Evaluations of Economic Inequality}

Economic inequality within industrialized countries has risen for the past half-century,

3 and its effects have been linked to various negative outcomes including poorer public health,, 2

4 higher rates of violence, ${ }^{3}$ increased support for authoritarian leadership, ${ }^{4}$ and diminished

5 resilience to global pandemics. ${ }^{5}$ Importantly, popular support for social and economic policies

6 that can lessen inequality —including healthcare, taxation, education, public assistance, and

7 beyond - is driven by people's subjective perceptions of inequality rather than by objective

8 levels of inequality. ${ }^{6,7,8}$ However, people's subjective estimates of inequality tend to be highly

\footnotetext{
${ }^{1}$ Nancy E Adler et al., "Relationship of Subjective and Objective Social Status with Psychological and Physiological Functioning: Preliminary Data in Healthy White Women," Health Psychology 19, no. 6 (2000): 58692, https://doi.org/10.1037//0278-6133.19.6.586.

${ }^{2}$ Ricardo Perez-Truglia, "The Effects of Income Transparency on Well-Being: Evidence from a Natural Experiment," American Economic Review 110, no. 4 (April 1, 2020): 1019-54, https://doi.org/10.1257/aer.20160256.

${ }^{3}$ Jeffrey D. Morenoff, Robert J. Sampson, and Stephen W. Raudenbush, "Neighborhood Inequality, Collective Efficacy, and the Spatial Dynamics of Urban Violence*," Criminology 39, no. 3 (2001): 517-58, https://doi.org/10.1111/j.1745-9125.2001.tb00932.x.

${ }^{4}$ Stefanie Sprong et al., "'Our Country Needs a Strong Leader Right Now': Economic Inequality Enhances the Wish for a Strong Leader,” Psychological Science 30, no. 11 (November 1, 2019): 1625-37, https://doi.org/10.1177/0956797619875472.

${ }^{5}$ J.A. Patel et al., "Poverty, Inequality and COVID-19: The Forgotten Vulnerable," Public Health 183 (June 2020): 110-11, https://doi.org/10.1016/j.puhe.2020.05.006.

${ }^{6}$ Engelhardt, C., \& Wagener, A. (2014). Biased perceptions of income inequality and redistribution.

${ }^{7}$ Gimpelson, V., \& Treisman, D. (2018). Misperceiving inequality. Economics \& Politics, 30(1), $27-54$.

${ }^{8}$ Judith Niehues, "Subjective Perceptions of Inequality and Redistributive Preferences: An International Comparison," n.d., 23.
} 


\section{HEURISTICS AND BIASES IN EVALUATIONS OF ECONOMIC INEQUALITY}

1 inaccurate, ${ }^{9,10,11,12}$ often formed by the limited, provincial experience of who they know, ${ }^{13,14}$

2 where they live, ${ }^{15}$ and the observable cues around them. ${ }^{16}$ This biases people's perceptions of

3 economic inequality and consequently shapes their political attitudes. ${ }^{17}$

It would seem natural, therefore, to expect that simply presenting people with accurate

information on economic distributions would correct their misperceptions. ${ }^{18}$ Indeed, such data

are frequently promulgated by social scientists, policymakers, and journalists as part of our

public discourse concerning economic inequality. However, providing information can only

correct misperceptions if people interpret this information in an unbiased manner. Unfortunately,

this does not appear to be the case. In this article we present eight pre-registered studies

$(\mathrm{N}=4188$, open science materials on $\underline{\text { ResearchBox }})$ in which we document two systematic biases

11 in people's evaluations of common presentations of economic distribution information. We show

12 that the most common ways of representing economic inequality inadvertently but predictably

\footnotetext{
${ }^{9}$ Guillermo Cruces, Ricardo Perez-Truglia, and Martin Tetaz, "Biased Perceptions of Income Distribution and Preferences for Redistribution: Evidence from a Survey Experiment," Journal of Public Economics 98 (2013): 100112, https://doi.org/10.1016/j.jpubeco.2012.10.009.

${ }^{10}$ Michael I. Norton and Dan Ariely, "Building a Better America - One Wealth Quintile at a Time," Perspectives on Psychological Science 6, no. 1 (January 2011): 9-12, https://doi.org/10.1177/1745691610393524.

${ }^{11}$ For additional considerations of Norton and Ariely (2011), see: K Eriksson and Brent Simpson, "What Do Americans Know about Inequality? It Depends on How You Ask Them," Judgment \& Decision Making 7, no. 6 (2012): 741-45; Michael I Norton and Dan Ariely, "American's Desire for Less Wealth Inequality Does Not Depend on How You Ask Them," Judgment and Decision Making 8, no. 3 (2013): 393-94.

${ }^{12}$ Indeed, in a pre-registered test, we found that most people had difficulty properly understanding wealth distributions even after completing an interactive training module. See Supplemental Materials for details.

${ }^{13}$ Juan Diego García-Castro, Guillermo B. Willis, and Rosa Rodríguez-Bailón, "I Know People Who Can and Who Cannot: A Measure of the Perception of Economic Inequality in Everyday Life," The Social Science Journal 56, no. 4 (December 1, 2019): 599-608, https://doi.org/10.1016/j.soscij.2018.09.008.

${ }^{14}$ Efraín García-Sánchez et al., "Perceptions of Economic Inequality in Colombian Daily Life: More Than Unequal Distribution of Economic Resources," Frontiers in Psychology 0 (2018), https://doi.org/10.3389/fpsyg.2018.01660.

${ }^{15}$ Michael W. Kraus, Jun Won Park, and Jacinth J. X. Tan, "Signs of Social Class: The Experience of Economic Inequality in Everyday Life," Perspectives on Psychological Science 12, no. 3 (May 1, 2017): 422-35, https://doi.org/10.1177/1745691616673192.

${ }^{16}$ Melissa L. Sands and Daniel de Kadt, "Local Exposure to Inequality Raises Support of People of Low Wealth for Taxing the Wealthy," Nature 586, no. 7828 (October 2020): 257-61, https://doi.org/10.1038/s41586-020-2763-1.

${ }^{17}$ Oliver P Hauser and Michael I Norton, “(Mis)Perceptions of Inequality," Current Opinion in Psychology 18 (December 2017): 21-25, https://doi.org/10.1016/j.copsyc.2017.07.024.

${ }^{18}$ For one account of the limited efficacy of such an approach, see: Ilyaba Kuziemko et al., "How Elastic Are Preferences for Redistribution? Evidence from Randomized Survey Experiments," The American Economic Review 105, no. 4 (2015): 1478-1508.
} 


\section{HEURISTICS AND BIASES IN EVALUATIONS OF ECONOMIC INEQUALITY}

1 distort people's perceptions of inequality. Indeed, an audit of the universe of popular American

2 newspapers' depictions of inequality information (see General Discussion) reveals that the most

3 common portrayals of such information foster biased interpretations. First, people are under-

4 sensitive to differences in the size of identified population groups. This results in greater

5 tolerance for inequality and lower support for redistributional policies when richer groups are

6 composed of fewer individuals than poorer groups (as when comparing the richest $10 \%$ versus

7 the rest of the country, for example). Second, people systematically over-weight information

8 about the richest and poorest groups relative to information about intermediate groups, resulting

9 in relative neglect of the prosperity of the middle class, independent of stated concern for their

10 well-being. Each of these biases influences the extent to which people support public policies

11 that redistribute wealth.

12 To illustrate our thesis, consider the following fact: the richest $10 \%$ of Americans

13 currently hold approximately three times the amount of wealth held by the rest of the country

14 (see Figure 1A, “Total Wealth"). Reflect for a moment on how fair or unfair this seems to you

15 and how strongly you would support redistributing wealth from richer to poorer people. Now

16 consider the fact that the average individual among the richest $10 \%$ holds 27 times as much

17 wealth as the average individual among the rest of the country (see Figure 1B, "Average

18 Wealth"). Although this second description is informationally equivalent to the first, it engenders

19 an impression of greater inequality. In Study 1, we surveyed 264 participants (55\% female, $\mathrm{M}_{\text {age }}$

$\left.20=38.8, \mathrm{SD}_{\mathrm{age}}=12.8\right)$ and found that just $26 \%$ of Americans support a policy to redistribute

21 wealth in an unidentified country when the distribution was represented as in Figure 1A.

22 However, more than twice as many people (53\%) supported such a policy when the same

23 underlying distribution was presented as in Figure 1B $\left(\chi^{2}=12.41, \mathrm{p}<0.001\right)$. 


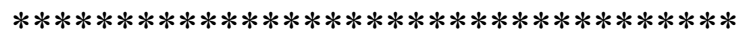

4 As predicted, we find that the distribution was rated as significantly less fair in the Average

5 Wealth condition than the Total Wealth condition $(b=-.79, t=-2.34, p<.05)$, and support for

6 redistribution was significantly greater in the Average Wealth than Total Wealth condition while

7 controlling for party identification $(b=1.40, t=3.39, p<.001)$. Interestingly, we observe a large

8 increase in support for redistribution among both self-identified Republicans and Democrats.

The observation that people exhibit inconsistencies when evaluating economic

distributions should not be surprising given the cognitive complexity involved: These

11 evaluations typically require comparisons of several population fractiles without any obvious

12 benchmarks for determining what is fair. Meanwhile, people's intuitions about fairness are better

13 suited for living in small groups rather than large-scale economies involving trillions of dollars

14 spread across millions of households. ${ }^{19,20}$

15 When judgment tasks are cognitively complex or taxing, people often rely on mental

16 shortcuts ("heuristics”) to simplify their judgments. ${ }^{21}$ In particular, two common effort-reducing

17 strategies involve decreasing the amount of information considered and simplifying the way in

18 which information is weighted. ${ }^{22}$ Thus, we propose that when evaluating the fairness of

19 economic distributions, people: (a) reduce information load by attending primarily to the most

\footnotetext{
${ }^{19}$ John Tooby and Leda Cosmides, "Human Cooperation Shows the Distinctive Signatures of Adaptations to SmallScale Social Life,” Behavioral and Brain Sciences 39 (2016): e54, https://doi.org/10.1017/S0140525X15000266.

${ }^{20}$ Steven M. Shugan, "The Cost of Thinking," Journal of Consumer Research 7, no. 2 (1980): 99-111.

${ }^{21}$ Daniel Kahneman, Paul Slovic, and Amos Tversky, Judgment under Uncertainty: Heuristics and Biases (Cambridge University Press, 1986), http://www.cog.brown.edu/courses/cg195/pdf_files/fall05/CG195TverskyKahn1974.pdf.

${ }^{22}$ Anuj K. Shah and Daniel M. Oppenheimer, "Heuristics Made Easy: An Effort-Reduction Framework.," Psychological Bulletin 134, no. 2 (2008): 207-22, https://doi.org/10.1037/0033-2909.134.2.207.
} 


\section{HEURISTICS AND BIASES IN EVALUATIONS OF ECONOMIC INEQUALITY}

1 salient groups, which are generally at the extremes of the distribution (i.e., the top and bottom

2 fractiles); and (b) simplify the weighting of information by relying on an equality heuristic, ${ }^{23}$

3 comparing a given distribution against a benchmark of equal allocation across groups. Taken

4 together, we refer to this strategy as the salient-group inequality (SGI) heuristic. We follow

5 Messick and Schell (1992) in assuming a bias toward equal allocation between groups, and we

6 further hypothesize (a) under-sensitivity to differences in population group sizes and (b) under-

7 sensitivity to information about less salient population groups.

8 The SGI heuristic implies two novel and testable hypotheses. First, fairness judgments

9 about economic distributions will vary systematically with the relative size of the groups into

10 which the population happens to be divided, a phenomenon called partition dependence. Second,

11 judgments of fairness will be relatively insensitive to variations in the amount of wealth held by

12 intermediate groups, a phenomenon we call middle neglect. In this paper we provide evidence of

13 both partition dependence and middle neglect, and we recommend strategies for overcoming

14 these pervasive biases.

15 Partition dependence in evaluation of economic distributions

16 The SGI heuristic asserts that people assess the fairness of economic distributions against

17 the natural benchmark of equality between explicitly identified groups. To the extent that people

18 give any weight to a group-level equality heuristic when evaluating the fairness of a given

19 distribution — while also being under-sensitive to differences in group sizes — their judgements

20 will vary systematically with the relative size and number of groups into which the population

${ }^{23}$ David M. Messick and Terry Schell, "Evidence for an Equality Heuristic in Social Decision Making," Acta Psychologica 80, no. 1-3 (August 1992): 311-23, https://doi.org/10.1016/0001-6918(92)90053-G. 


\section{HEURISTICS AND BIASES IN EVALUATIONS OF ECONOMIC INEQUALITY}

1 happens to be partitioned. ${ }^{24}$ In other words, an equality heuristic on its own is not enough to give

2 rise to partition-dependent preferences, but a corresponding insensitivity to differences in group

3 sizes will give way to preferences that vary with seemingly inconsequential decisions about how

4 to represent inequality information. For instance, when evaluating the allocation of wealth

5 between the richest $50 \%$ and poorest $50 \%$, a bias toward equality implies a bias toward

6 allocating half the wealth to each group. However, when the top 50\% is subdivided quasi-

7 logarithmically into \{top $1 \%$, next $4 \%$, next $15 \%$, next $30 \%$, a bias toward equality between

8 groups implies a bias toward allocating four-fifths of national wealth to the richest $50 \%$ and one-

9 fifth to the poorest $50 \%$.

10 In Study 2, we tested this prediction by asking 165 American participants to characterize

11 how they thought wealth ideally should be distributed in the United States $\left(44 \%\right.$ female, $\mathrm{M}_{\text {age }}=$

$\left.1236.1, \mathrm{SD}_{\mathrm{age}}=11.8\right)$. We randomly assigned participants to one of two versions of this task in

13 which the population was partitioned into five fractiles either equally or quasi-logarithmically

14 (Figures 2A-B). We note that these are two common ways for the popular press to present wealth

15 distributions (see, for instance, Figure 4A). "Unpacking" the top $20 \%$ of the population from

16 one group out of five (as in Figure 2A) into three groups out of five (Figure 2B) resulted in an

17 increase in the share of total national wealth that participants said the top quintile ought to hold

18 from $44 \%$ to $64 \%(t(152)=4.82, \mathrm{p}<0.001)$.

\footnotetext{
${ }^{24}$ Craig R. Fox, Rebecca K. Ratner, and Daniel S. Lieb, "How Subjective Grouping of Options Influences Choice and Allocation: Diversification Bias and the Phenomenon of Partition Dependence.," Journal of Experimental Psychology: General 134, no. 4 (2005): 538-51, https://doi.org/10.1037/0096-3445.134.4.538.

25 "Wealth Inequality in the United States," in Wikipedia, July 18, 2020, https://en.wikipedia.org/w/index.php?title=Wealth_inequality_in_the_United_States\&oldid=968351261.
} 
4 Interestingly, we observed similar treatment effects when we asked participants to estimate the

5 current wealth distribution in the United States, suggesting that the impact of partitioning extends

6 from normative preferences to descriptive estimates ( $c f$. Norton and Ariely, 2011). ${ }^{26}$ These

7 effects of condition hold controlling for political preferences (see Supplement Study 2). Thus, we

8 confirmed our prediction that participants would exhibit a (partition-dependent) bias toward

9 equal allocation across identified fractiles, with insufficient sensitivity to the relative size of

10 these fractiles.

11 In two additional studies, we tested the robustness of partition dependence. In Study 3, 12 we asked 162 participants $\left(51 \%\right.$ female, $\left.\mathrm{M}_{\mathrm{age}}=37.7, \mathrm{SD}_{\mathrm{age}}=11.8\right)$ to report their estimated and

13 ideal wealth distributions for the United States using an alternative partitioning scheme,

14 unpacking the top of the wealth distribution into evenly spaced population groups, either $\{50$ -

$1550\}$ or $\{10-10-10-10-10-50\}$. As predicted, participants allocated significantly more wealth to

16 the top half of the distribution when it was subdivided into five fractiles (68\%) compared to

17 when it was a single fractile $(60 \% ; \mathrm{t}=-3.16, \mathrm{p}<.002)$. Again, we found a similar effect for

18 descriptive views of how wealth is thought to be currently allocated as well as normative views

19 of how wealth ought to be allocated. In Study $4\left(\mathrm{~N}=140,44 \%\right.$ female, $\left.\mathrm{M}_{\text {age }}=39.0, \mathrm{SD}_{\text {age }}=12.9\right)$,

20 we found that partition dependence for ideal distributions persisted even when we provided

21 participants with the actual current U.S. wealth distribution as a point of reference. Controlling

22 for political preferences, participants allocated significantly more wealth to the top half of the

\footnotetext{
${ }^{26}$ Eriksson and Simpson, "What Do Americans Know about Inequality? It Depends on How You Ask Them."
} 


\section{HEURISTICS AND BIASES IN EVALUATIONS OF ECONOMIC INEQUALITY}

1 distribution when confronted with a $\{10-10-10-10-10-50\}$ partition than when confronted with a

$2\{25-25-50\}$ partition $(b=7.99, t=2.78, p<0.01)$. As before, a seemingly inconsequential decision

3 about how to group the population when eliciting preferences led to a considerable increase in

4 participants' stated tolerance of inequality.

5 One obvious way to mitigate partition dependence is to present information using equally

6 spaced population bins. Indeed, this makes direct comparisons between groups straightforward

7 and circumvents the problem of partition dependence. However, there is often good reason for

8 wanting to make comparisons between unequally sized population groups. For instance, wealth

9 is often extremely concentrated at the very top of the distribution, as is the case in the United

10 States. Presenting the wealth held by the top quintile would mask extreme levels of inequality

11 within this group (e.g., when the top $1 \%$ or top $0.1 \%$ hold vastly more wealth than others in the

12 top quintile). Alternatively, a social scientist may wish to explicitly compare the relative sizes of

13 the groups among which wealth is concentrated, as when comparing the wealth of the richest

$1410 \%$ against the wealth of the poorest $90 \%$. In these cases, while there is good reason to compare

15 population groups of different sizes, the level of perceived inequality is likely to be

16 systematically diminished if economic information is presented using a metric such as total

17 wealth (see again, for instance, Figures $2 \mathrm{a}$ and $2 \mathrm{~b}$ ), as shown in Study 1.

18 For such comparisons to be direct and meaningful, the metrics must account for

19 differences in group size. Thus, partition dependence can be mitigated by presenting economic

20 distributions using a metric that is partition-invariant such that the total amount of wealth or

21 income is scaled by the size of each group (for instance, the "average wealth per individual" or

22 "percent of national income per percentile" for each group). Such scaled metrics facilitate more

23 direct comparisons of the economic distributions across population groups. 


\section{HEURISTICS AND BIASES IN EVALUATIONS OF ECONOMIC INEQUALITY}

Testing this notion, in Study 5, we randomly assigned 679 participants to one of four conditions in a 2 (population partition: quintiles vs. quasi-logarithmic) x 2 (metric: percentage of

3 total wealth vs. percent-per-percentile $)$ experimental design $\left(56 \%\right.$ female, $\mathrm{M}_{\text {age }}=37.7, \mathrm{SD}_{\text {age }}=$

4 12.0). We presented each participant with the wealth distribution of an unidentified country

5 (approximating the distribution in the United States) using one of these four presentation

6 formats. Participants judged the fairness of the wealth distribution then rated their preferences for

7 redistribution in this society. The difference between a total wealth and average wealth metric

8 was considerably smaller for equally spaced population groups $(b=-.61, t=-2.10, p<.05)$ versus

9 the harder-to-compare unequally spaced groups $(b=.87, t=2.91, p<.01)$. Stated another way, the

10 effect of partitioning — quintiles versus logarithmic grouping — is considerably smaller when

11 using an average wealth metric compared to a total wealth metric $\left(b_{\text {interaction }}=1.48, \mathrm{t}=3.56\right.$,

$12 \mathrm{p}<.001)$. This suggests that economic inequality ought to be represented using scaled, partition-

13 invariant metrics, especially when making comparisons between unequally sized population 14 groups.

15 We pause here to note that, although we have demonstrated that people's support for

16 redistribution is affected by their subjective impression of the degree of inequality, we do not

17 mean to suggest that people's attitudes toward inequality and redistribution exclusively derive

18 from these impressions. People also have principled notions regarding the fairness and

19 justifiability of inequality, ${ }^{27}$ often stemming from their lay theories about the fundamental causes

\footnotetext{
${ }^{27}$ Christina Starmans, Mark Sheskin, and Paul Bloom, "Why People Prefer Unequal Societies," Nature Publishing
} Group 1, no. 0082 (2017), https://doi.org/10.1038/s41562-017-0082. 


\section{HEURISTICS AND BIASES IN EVALUATIONS OF ECONOMIC INEQUALITY}

1 of economic inequality. ${ }^{28,29,30}$ However, impressions of how wealth and income are distributed

2 do have a considerable impact on people's judgments of the fairness of a society and their

3 support for policies that redistribute wealth, as demonstrated throughout this article and

4 elsewhere. $^{31}$

\section{$5 \quad$ Middle neglect in evaluation of economic distributions}

The foregoing studies provide evidence consistent with the notion that people reduce complexity inherent in evaluating economic distributions by simplifying the weighting of cues

8 (notably, by comparing the given distribution against equality between groups). In addition, we

9 propose that people reduce complexity by disproportionately attending to the most salient groups

10 and neglecting others. The richest and poorest groups generally command the greatest attention

11 due to their symbolic importance and because they are usually listed first and last. Therefore,

12 people may be systematically under-sensitive to allocations to intermediate population groups.

13 Thus, we conjecture that this bias results not from a principled disregard of the middle class but

14 rather a tendency to direct attention toward more salient information - in this case, typically the

15 richest and poorest groups in a distribution. ${ }^{32}$ Indeed, it is common among media and policy

16 reports of inequality to simplify information by neglecting intermediate groups entirely (e.g.,

\footnotetext{
${ }^{28}$ Job Krijnen et al., "Lay Theories of Financial Well-Being Predict Political and Policy Message Preferences," Journal of Personality and Social Psychology, 2021.

${ }^{29}$ Paul K. Piff et al., "Shifting Attributions for Poverty Motivates Opposition to Inequality and Enhances Egalitarianism," Nature Human Behaviour, March 16, 2020, 1-10, https://doi.org/10.1038/s41562-020-0835-8.

${ }^{30}$ Pia Dietze and Maureen A. Craig, "Framing Economic Inequality and Policy as Group Disadvantages (versus Group Advantages) Spurs Support for Action," Nature Human Behaviour 5, no. 3 (March 2021): 349-60, https://doi.org/10.1038/s41562-020-00988-4.

${ }^{31}$ Hauser and Norton, "(Mis)Perceptions of Inequality."

${ }^{32}$ We note that the claim of middle neglect is only that people are under-sensitive to information about intermediate fractiles (relative to the first and last fractiles), not that they are entirely insensitive to them. Thus, for instance, anything that heightens the salience of or draws explicit attention to these middle fractiles will likely attenuate middle neglect.
} 


\section{HEURISTICS AND BIASES IN EVALUATIONS OF ECONOMIC INEQUALITY}

1 “The 3 Richest Americans Hold More Wealth Than Bottom 50\% Of The Country, Study

2 Finds"). ${ }^{33}$

3 In Study 6, we tested for middle neglect by asking 197 participants to rate the fairness of

4 eight different hypothetical wealth distributions ( $41 \%$ female, $\left.\mathrm{M}_{\text {age }}=34.6, \mathrm{SD}_{\mathrm{age}}=11.4\right)$. We

5 varied the average income for each of three population segments. The richest quintile of society

6 was described as having an average annual income of either $\$ 220,000$ or $\$ 440,000$, the middle

7 quintile having an average of either $\$ 60,000$ or $\$ 120,000$, and the poorest quintile having an

8 average of either $\$ 14,000$ or $\$ 28,000$. Participants observed and rated all eight of the possible

9 combinations of incomes.

The results support our prediction of middle neglect. Doubling the average income of the

11 richest group led respondents to rate a distribution as significantly less fair $(b=-0.730, S E=0.101$,

$12 \mathrm{p}<.001)$, and doubling average income of the poorest group led respondents to rate a distribution

13 as significantly more fair $(b=1.199, \mathrm{SE}=0.125, \mathrm{p}<0.001)$. However, doubling the average income

14 of the middle third of society had considerably less impact on fairness judgments $(b=0.128$,

$15 \mathrm{SE}=0.076, \mathrm{p}=0.094, N S)$, despite the objective increase in equality as measured by the GINI

16 coefficient. $^{34}$

17 Further, we assessed whether sensitivity to the well-being of each population group is

18 affected by people's stated priorities when evaluating economic distributions. To do so, we asked

19 participants to rate the following four statements (order counter-balanced between participants),

20 using a -7 (completely disagree) to +7 (completely agree) scale:

\footnotetext{
${ }^{33}$ http://tiny.cc/richest3See, for instance: Federal Reserve, 2017; Occupy Wall Street, X; US Census Bureau, Y; World Economic Inequality Report, 2015; UNDP, 2019; World Bank, 2015;

34 The Gini Coefficient, a measure of wealth concentration, is calculated as the amount of deviation from perfect equality.
} 
HEURISTICS AND BIASES IN EVALUATIONS OF ECONOMIC INEQUALITY

22 categories: $:^{35}$ can.

1. We ought to make sure that the POOREST members of society are doing as well as they

2. We ought to reduce the amount of inequality between the TOP and BOTTOM groups in society.

3. We ought to make sure that it is possible to become EXTREMELY WEALTHY to incentivize people.

4. We ought to build as strong, robust and wealthy of a MIDDLE class as possible.

These measures allowed us to complete two secondary analyses (see Supplement Study 6). First,

we find that the pattern of results described above holds even when controlling for people's

stated concern for each of these groups. Second, we examined whether stated concern for a given group moderated the effect of doubling that group's income. While sensitivity to income changes among the richest and poorest quintiles was moderated by a stated concern for these groups, respectively, we found no greater sensitivity to income changes of the middle class among those with a greater self-reported concern for the middle class. These findings suggest that middle neglect might reflect a bias in information processing rather than a principled desire to prioritize the rich or the poor.

To explore middle neglect further, in Study 7 we asked 269 participants to rate the fairness of a wealth distribution that approximated current levels of inequality in the United States, and to indicate their level of support for redistributional policies $\left(53 \%\right.$ female, $\mathrm{M}_{\mathrm{age}}=38.3$, $\mathrm{SD}_{\text {age }}=12.0$ ). Next, we prompted participants to list the thoughts that occurred to them as they made their evaluation, and then label each of their own thoughts using one of six predetermined

\footnotetext{
${ }^{35}$ Eric J. Johnson, Gerald Häubl, and Anat Keinan, “Aspects of Endowment: A Query Theory of Value Construction.," Journal of Experimental Psychology: Learning, Memory, and Cognition 33, no. 3 (2007): 461-74, https://doi.org/10.1037/0278-7393.33.3.461.
} 
HEURISTICS AND BIASES IN EVALUATIONS OF ECONOMIC INEQUALITY

- I focused on how much of the total wealth was concentrated at the TOP of the distribution

- I focused on how much of the total wealth was at the BOTTOM of the distribution

- I focused on the DIFFERENCE between the amount of wealth at the TOP vs the BOTTOM of the distribution

- I focused on the RATIO of wealth at TOP to wealth at the BOTTOM of the distribution

- I focused on how much of the total wealth was held by the MIDDLE of the distribution

- I focused on how much the distribution differed from total equality across groups

- Other

The two most common categories of thoughts were total wealth held by the richest group (210 instances) and difference between the richest and poorest groups (178 instances). The least frequently mentioned category was middle of the distribution (52 instances).

We have attributed middle neglect to information overload, which is especially problematic in common textual and tabular presentations of income distributions. One way to potentially overcome this limitation is to display distributions visually, which can facilitate simultaneous processing of more information for data like these. ${ }^{36}$ Thus, in Study 8 we examined whether middle neglect can be attenuated by displaying the same information visually rather than tabularly. We presented 394 participants with a pair of wealth distributions over four quartiles (50\% female, $\left.\mathrm{M}_{\mathrm{age}}=39.2, \mathrm{SD}_{\mathrm{age}}=11.6\right)$. One of these distributions had a larger gap between the richest and the poorest quartiles but a smaller gap between intermediate quartiles ("Middle Fair"). The other distribution had a smaller gap between the richest and poorest quartiles but a larger gap between the intermediate quartiles ("Top-Bottom Fair"). Participants were randomly assigned to either a "Tabular" condition in which information was presented numerically (see Figure 3A) or a "Graphical" condition in which the same information was presented visually (see Figure 3B).

\footnotetext{
${ }^{36}$ S. L. Jarvenpaa and G. W. Dickson, "Graphics and Managerial Decision Making: Research-Based Guidelines," Communications of the ACM 31, no. 6 (June 1988): 764-74, https://doi.org/10.1145/62959.62971.
} 
4 We then asked participants to select the distribution that "seems more fair" to them. Consistent

5 with our prediction, we found that participants were more than twice as likely to choose the

6 Middle Fair distribution in the graphical condition (30\%) than the tabular condition $\left(13 \%, \chi^{2}(1\right.$,

$7393)=15.14, p<0.001$ ). Thus, people appear to afford greater weight to middle groups when

8 information is presented visually, and they appear to focus more on top-bottom comparisons

9 when information is presented in the more cognitively demanding tabular format. ${ }^{37}$

\section{Minimizing Biases in Evaluations of Economic Inequality}

11 In this paper, we have presented evidence of two systematic biases in people's reported

12 preferences regarding economic inequality: (1) partition dependence, a bias toward comparing

13 the allocation between population groups without adequate sensitivity to differences in the

14 relative size of these groups, and (2) middle neglect, the tendency to overweight the amount

15 allocated to the richest and poorest groups (compared to intermediate groups) due to their

16 relative salience. We have demonstrated that partition dependence can be mitigated by

17 presenting information about economic distributions using partition-invariant metrics such as

18 average wealth per person in each population group. Middle neglect can be mitigated through the

19 use of visual displays that facilitate more even attention across groups. We therefore recommend

20 that when presenting data or soliciting preferences concerning economic inequality, journalists,

\footnotetext{
${ }^{37}$ Given how consequential intermediate fractiles are to the Gini Coefficient and other measures of inequality, visual displays can thus shift preferences between two very different levels of inequality through increased attention to the middle.
} 


\section{HEURISTICS AND BIASES IN EVALUATIONS OF ECONOMIC INEQUALITY}

1 researchers, pollsters, and policymakers should use: (1) partition-invariant metrics and (2) visual

2 displays.

A solution that combines both of these recommendations is a proportional visual display

4 ("PVD") as illustrated in Figure 4B, in contrast to the more common presentation format

5 displayed in Figure $4 a .^{38}$

6

9 In PVDs, the money held by each population group (i.e., the height of bars in Figure 4B) is

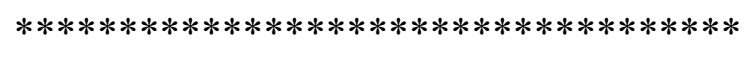

Insert Figures 4A-B here expressed using a partition-invariant metric, and the size of each population group (i.e., the width of each bar in Figure 4B) is visually represented in proportion to the number of individuals included in each group, highlighting the proportion of the population at each level of wealth. Thus, PVDs minimize both partition dependence and middle neglect. Currently, most presentations of economic distributions in the popular press are neither proportional nor visual. To investigate how popular outlets typically portray this information, we conducted an audit of every article mentioning income or wealth inequality in the year 2020 among the eight most popular print newspapers in America (see Supplementary Materials for more details). Of the 2,958 articles that we reviewed, only $2 \%$ (58 articles) contained visual representations of inequality, $74 \%$ of which compared unequally sized groups. Of the 335 articles that instead contained a verbal description of how money is allocated across society—an average of nearly one article per day_most did so in ways that foster biased impressions of

\footnotetext{
${ }^{38}$ For a related approach, see Lionel Page and Daniel G. Goldstein, "Subjective Beliefs about the Income Distribution and Preferences for Redistribution," Social Choice and Welfare 47, no. 1 (June 2016): 25-61, https://doi.org/10.1007/s00355-015-0945-9.
} 


\section{HEURISTICS AND BIASES IN EVALUATIONS OF ECONOMIC INEQUALITY}

1 inequality: comparing unequally sized groups (94\% of articles), using an aggregate metric rather

2 than a scaled metric (62\%), and explicitly drawing attention to the extremes of the distribution

3 while failing to consider intermediate groups (57\%). In fact, nearly two-thirds (63\%) of the

4 articles using unequally sized groups also used a partition-dependent metric, exacerbating the

5 problem. Moreover, these problems are not limited to the popular press - highly cited academic

6 articles $^{39}$ as well as reports produced by esteemed institutions ${ }^{40}$ present information on economic

7 inequality using similar formats. As we have observed, these presentations facilitate biases in

8 people's perceptions, which in turn distorts their attitudes toward government policies that can

9 mitigate economic inequality. This, we think, can partially explain why public perceptions of

10 inequality tend to be so inaccurate ${ }^{41}$ despite frequent presentations of objectively accurate

11 information about economic inequality in the popular press.

12 Although we have focused on perceptions of economic inequality, we hasten to add that

13 the biases we have identified — partition dependence and middle neglect—likely apply much

14 more broadly to various kinds of judgments concerning various kinds of distributions. We have

15 focused here on perceptions of economic inequality both because of its social importance and

16 because of its ubiquity. This said, the underlying psychology of partition dependence and middle

17 neglect is relevant to judgments concerning any ordered distribution — for instance, when

18 evaluating the inequality in greenhouse gas emissions by country, the number of National Merit

19 scholars per school district, the distribution of virus positivity between states, and so forth.

Many of our most important and heated political debates revolve around government

21 policies that redistribute wealth. Preferences for redistribution are largely driven by how people

\footnotetext{
${ }^{39}$ For instance, Norton and Ariely (2011) present information in tabular form, thereby facilitating middle neglect. Picketty, Saez and Zucman (2016), for instance, use unequal group sizes facilitating partition dependence.

${ }^{40}$ For instance, the US Census Bureau, the Pew Research Center, and the World Inequality Database

${ }^{41}$ Hauser and Norton, "(Mis)Perceptions of Inequality."
} 


\section{HEURISTICS AND BIASES IN EVALUATIONS OF ECONOMIC INEQUALITY}

1 view prevailing levels of inequality. In this paper we have shown that subtle variations in the

2 presentation of economic distributions can bias people's assessments of economic fairness and

3 thereby influence their support for redistributional policies. In fact, we find that these biases can

4 affect support for redistributional policies as strongly as differences in political affiliation. We

5 document these effects even among informed participants who undergo rigorous, dynamic

6 training that demonstratively improves comprehension of information on economic distributions

7 (see Supplement Pilot Study for more details). We argue that presenting information visually and

8 using metrics that are scaled by group size can help overcome partition dependence and middle

9 neglect, thereby promoting more rational policy decisions. 


\section{Figure 1 Notes:}

In Study 1, Figures 1A and 1B present informationally equivalent representations of the current approximate wealth distribution in the United States, described in terms of total wealth (Fig. 1a) and average wealth per person (Fig. 1b).

Figure 1A

Wealth Distribution:

Share of total national wealth

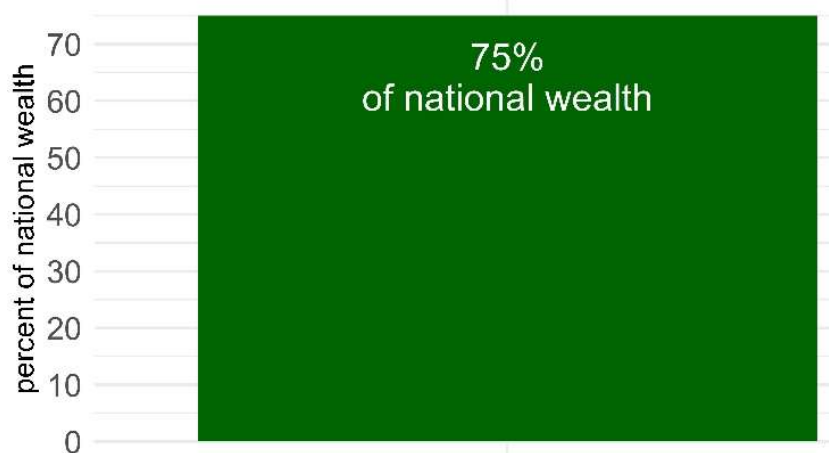

Richest $10 \%$

of people

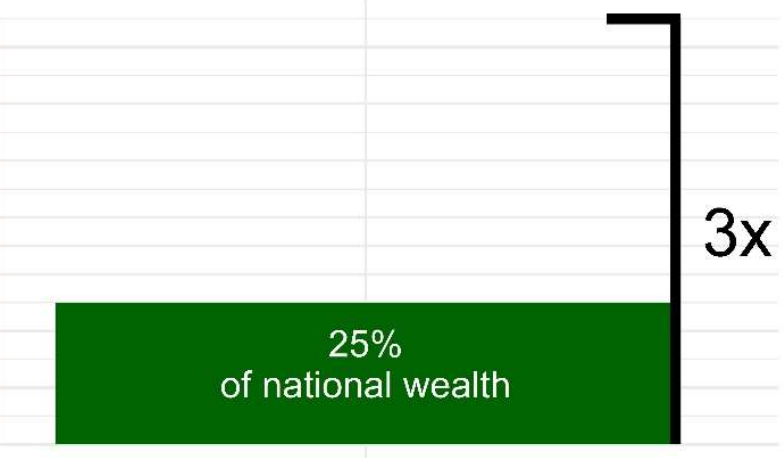

Poorest 90\% of people

Figure 1B

Wealth Distribution:

Average share of national wealth per percentile

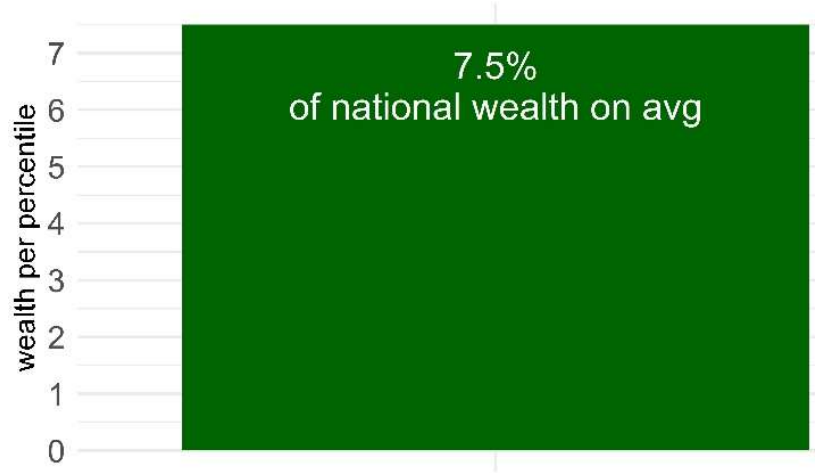

Richest $10 \%$

of people

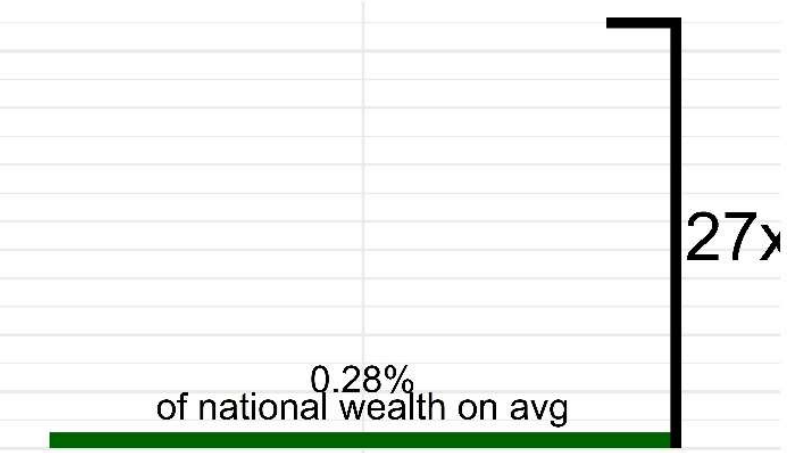

Poorest $90 \%$ of people 


\section{HEURISTICS AND BIASES IN EVALUATIONS OF ECONOMIC INEQUALITY}

\section{Figure 2 Notes:}

In Study 3, subjects constructed ideal wealth distributions using either five evenly divided groups (Figure 2A) or five quasi-logarithmically divided groups (Figure 2B).

\begin{tabular}{|c|c|}
\hline $\begin{array}{l}\text { What percent of the United } \\
\text { American control? }\end{array}$ & th should the following groups of \\
\hline Figure 2A & Figure 2B \\
\hline Richest 20\% & Richest 1\% \\
\hline Next $20 \%$ & Next $4 \%$ \\
\hline Next $20 \%$ & Next $15 \%$ \\
\hline Next $20 \%$ & Next $30 \%$ \\
\hline Poorest $20 \%$ & Poorest 50\% \\
\hline
\end{tabular}




\section{HEURISTICS AND BIASES IN EVALUATIONS OF ECONOMIC INEQUALITY}

\section{Figure 3 Notes:}

In Study 9, subjects chose which distribution seemed more fair when the options were presented either tabularly (Figure 3A) or graphically (Figured 3B).

Figure 3A

\begin{tabular}{|c|c|}
\hline Percent of Population & $\begin{array}{c}\text { Percent of Wealth } \\
\text { They Own }\end{array}$ \\
\hline Richest 25\% of people & $50 \%$ \\
\hline Next $\mathbf{2 5 \%}$ of people & $29 \%$ \\
\hline Next $\mathbf{2 5 \%}$ of people & $18 \%$ \\
\hline Poorest $\mathbf{2 5 \%}$ of people & $3 \%$ \\
\hline
\end{tabular}

Figure 3B

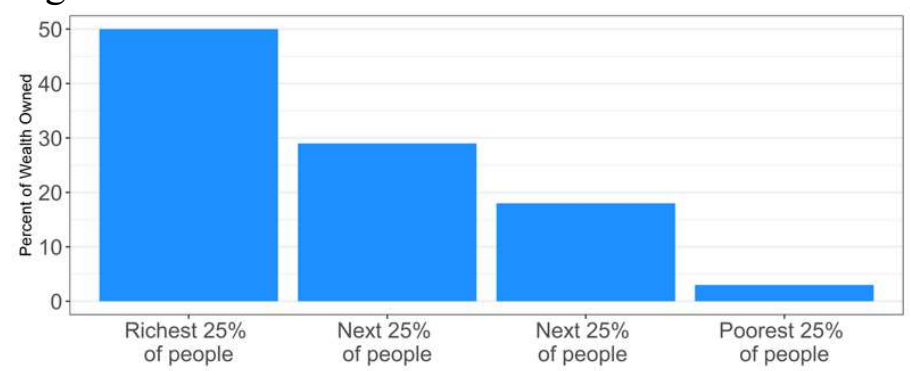

\begin{tabular}{|c|c|}
\hline Percent of Population & $\begin{array}{c}\text { Percent of Wealth } \\
\text { They Own }\end{array}$ \\
\hline Richest $\mathbf{2 5 \%}$ of people & $40 \%$ \\
\hline Next $\mathbf{2 5 \%}$ of people & $38 \%$ \\
\hline Next $\mathbf{2 5 \%}$ of people & $12 \%$ \\
\hline Poorest $\mathbf{2 5 \%}$ of people & $10 \%$ \\
\hline
\end{tabular}

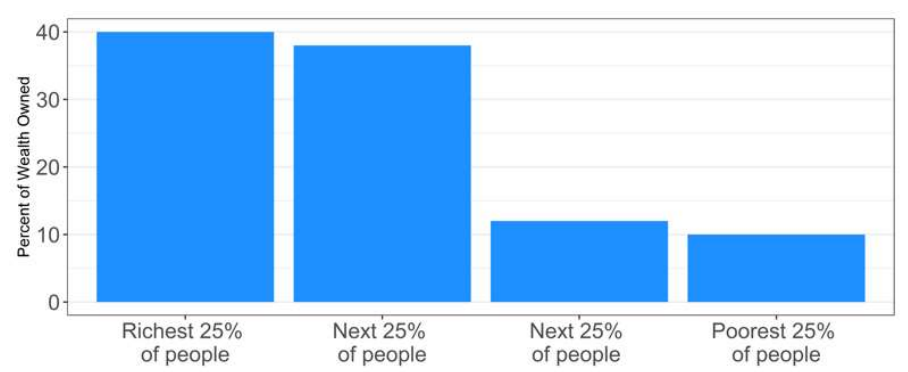




\section{HEURISTICS AND BIASES IN EVALUATIONS OF ECONOMIC INEQUALITY}

\section{Figure 4 Notes:}

Figure 4A provides an example of how wealth inequality is typically represented in the popular press. Figure 4B presents the same distribution as a proportional visual display (PVD).

Figure 4A
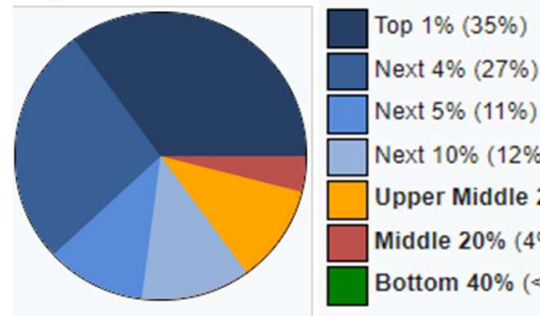

Distribution of net worth in the

United States (2007) ${ }^{[20]}$ The net

wealth of many people in the lo
$20 \%$ is negative because of

debt. ${ }^{[20]}$ By 2014 the wealth gap

deepened. [oitation needeol]

Figure 4B

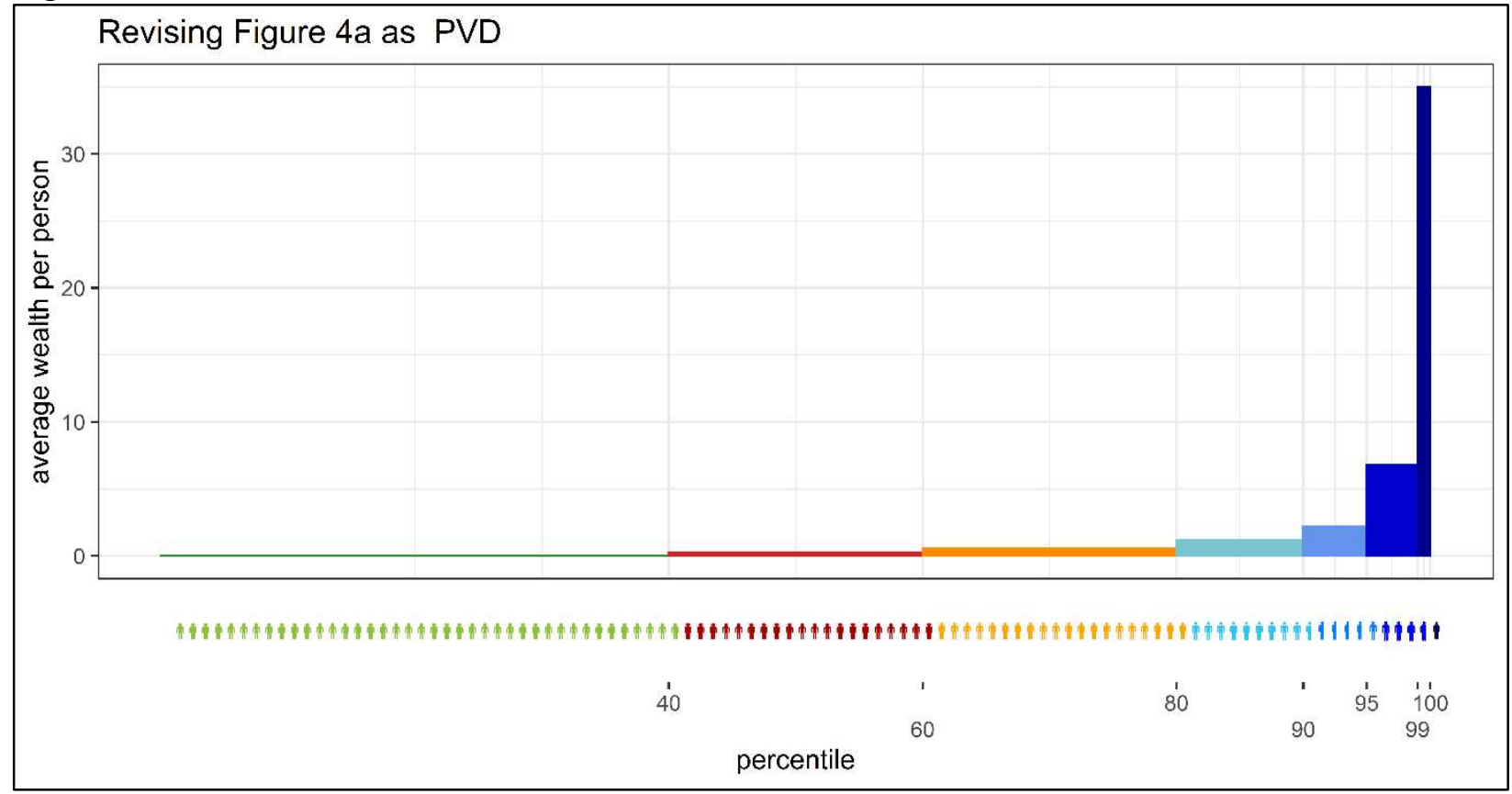




\section{Supplementary Materials for}

\section{Heuristics and Biases in Evaluations of Economic Inequality}

This file includes:

- Pilot study methods and results

- Additional methodological detail for each study

- Figures S1-S5

- Tables S1-S9

All preregistrations, survey materials, data, and code are available on the Open Science Framework: http://tiny.cc/bwfHBEEI

\section{Pilot Study: Misperceptions of Inequality}

In a pilot study, we examine misunderstandings and misperceptions when people evaluate economic distributions. We find that this is a deceptively difficult task for most people. We conducted an experiment to identify the specific errors that people make and how these errors influence people's opinions of national economic distributions. Further, we test to see if the training module we designed significantly reduces the errors that people make when making judgments and decisions about such distributions.

1.1 Methods and Participants. In the Pilot study included with Study 2, we recruited 251 participants from Amazon's Mechanical Turk who passed pre-registered inclusion criteria of passing an attention check and spending at least 6 minutes on the full survey $\left(51 \%\right.$ female, $\mathrm{M}_{\text {age }}$ $\left.=38.4, \mathrm{SD}_{\text {age }}=12.6\right)$. Participants were randomly assigned between-subjects to one of two conditions: Training or No Training. Participants in the Training condition completed a sevenminute interactive training module designed to introduce the core concepts of wealth distributions: Population percentiles, allocation of a fixed percentage of a resource, calculating average allocation per percentile, and monotonic allocations. This Training module contained definitions, descriptions and examples, and it had interactive questions where participants answered a question and then were shown a correct answer. At the end of the training module, participants responded to three comprehension questions (e.g., "If you gave $30 \%$ of total wealth to the richest $10 \%$ of people in the United States, how much wealth is remaining to be distributed to the rest of the population?"). After this, participants completed the Ideal Allocation Task, constructing their ideal allocation of wealth across five population quintiles, and the Descriptive Allocation Task, constructing what they believed to be the current distribution of wealth across the five quintiles (tasks based on Norton and Ariely, 2011). Participants in the No Training condition first completed the Ideal and the Descriptive Allocation Task, and then answered the comprehension questions. The order of the Ideal and Descriptive Allocation Tasks was randomized between participants. 


\section{HEURISTICS AND BIASES IN EVALUATIONS OF ECONOMIC INEQUALITY}

We captured three measures of miscomprehension: errors on the comprehension questions, failure to allocate $100 \%$ of national wealth across population groups, and violations of monotonicity (allocating of a larger share of wealth to a definitionally poorer group). For instance, the following allocation represents the actual response of a participant who violated monotonicity in the Ideal Allocation Task.

Table S1. Example of a participant response in the Pilot Study that violated monotonicity

\begin{tabular}{|c|c|}
\hline $\begin{array}{c}\text { Population } \\
\text { Group }\end{array}$ & $\begin{array}{c}\text { Percent of National Wealth they SHOULD } \\
\text { Control }\end{array}$ \\
\hline Richest 20\% & $50 \%$ \\
\hline Next 20\% & $10 \%$ \\
\hline Next 20\% & $10 \%$ \\
\hline Next 20\% & $10 \%$ \\
\hline Poorest 20\% & $20 \%$ \\
\hline Total & $100 \%$ \\
\hline
\end{tabular}

As can be seen, this participant suggested that the poorest quintile of Americans should hold twice as much wealth as the next-richest quintile of Americans. We were interested in how pervasive these sorts of errors were and, secondarily, whether training helped to mitigate them.

Norton and Ariely (2011) found that an unreported number of participants in their study violated monotonicity (the authors simply corrected this mistake for participants by rearranging allocation amounts monotonically) and others failed to allocate exactly $100 \%$ of national wealth (the authors rescaled participants' responses for them). While, in this study and in all subsequent ones using this paradigm, we made sure that this latter error would not result from a simple arithmetic error by displaying a live-updating sum of the share of wealth participants had allocated, we were curious whether these mistakes were in fact indicative of a deeper misunderstanding rather than a simple mistake.

1.2 Results. We find evidence for pervasive misunderstandings of economic distributions. Without training, $75 \%$ of participants made at least one error and $27 \%$ made the fundamental error of violating monotonicity. Figure 1 shows the number of people remaining in the sample after removing participants who made each specific error type (failed to sum to $100 \%$ of national wealth, violated monotonicity, and answered the comprehension questions correctly).

Figure S1. Pilot Study errors in the condition where participants did not receive training on understanding economic distributions 


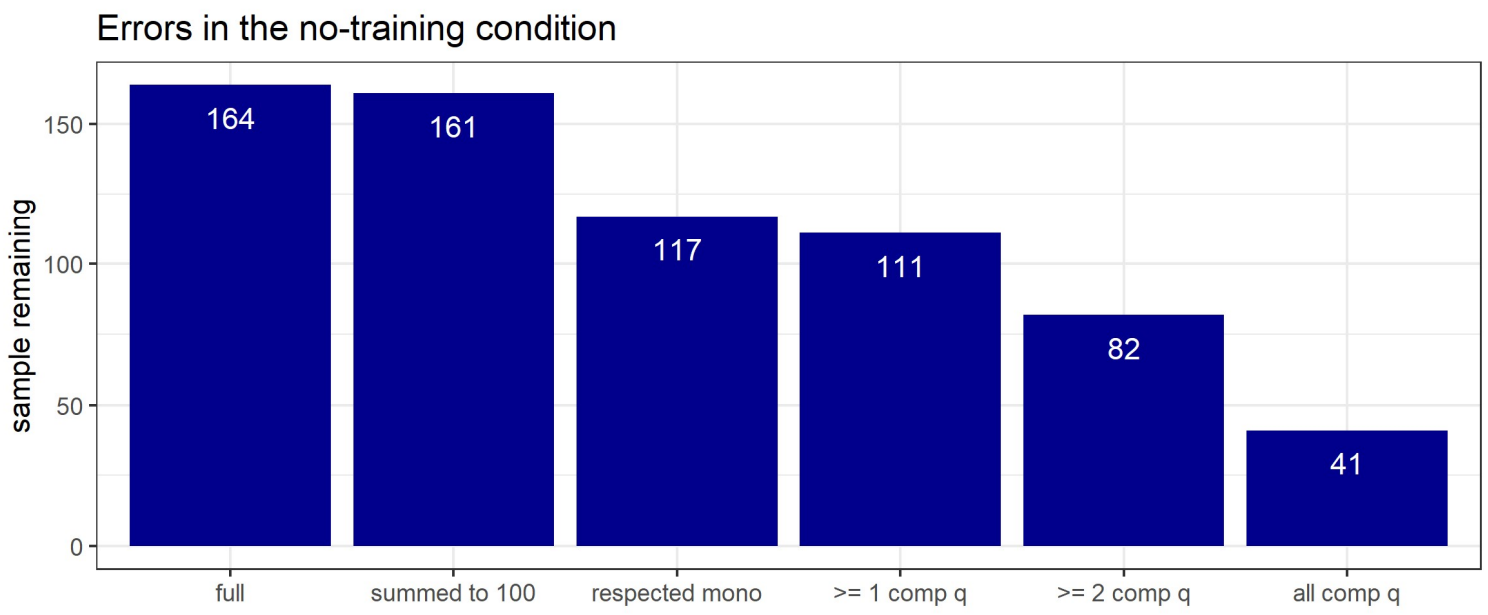

Notes: Displaying resultant sample after removing participants who failed each respective measure of comprehension in the Ideal Allocation Task.

While the training module successfully reduced violations of monotonicity from $27 \%$ to $15 \%$ $\left(\chi^{2}(1,251)=3.92, p<.05\right)$, these results show that full comprehension of the task seems to be deceptively hard for a large share of people.

\section{Study 1: Unit Dependence}

The purpose of Study 1 was to demonstrate unit-dependence, that people's judgments of the fairness of unevenly partitioned population groups would be influenced by the metrics used to express economic inequality. We pre-registered a prediction that people would perceive distributions to be less unfair and they would have lower support for redistributional policies when inequality was expressed using the (commonplace) metric of Total Wealth compared to a metric that scales by population size (i.e., average wealth).

2.1 Methods and Participants. In Study 1, we recruited 264 participants from Amazon's Mechanical Turk who met pre-registered inclusion criteria $\left(55 \%\right.$ female, $\mathrm{M}_{\mathrm{age}}=38.8, \mathrm{SD}_{\mathrm{age}}=$ 12.8). Participants were asked their opinions about how wealth is distributed in an unnamed "Western, democratic" country (the information we provided approximated the current wealth distribution in the United States, but participants were not informed of this). Participants were then randomly assigned to either a Total Wealth or Average Wealth condition in which the same distribution of wealth was presented in different formats. In the Total Wealth condition, participants were presented with the wealth held by the richest $10 \%$ and poorest $90 \%$ of people using a metric of total national wealth. In the Average Wealth condition, this information was presented using a metric of average wealth per percentile (Figures 1A and 1B).

Participants then responded to two questions: "In your opinion, how fair is this distribution?" (-5=completely unfair, $0=$ neither fair nor unfair, $5=$ completely fair), and "Given 
this distribution, to what extent would you support a government policy that redistributes wealth from richer to poorer individuals?" $(-5=$ strongly oppose, $0=$ neither oppose nor support, $5=$ strong support). We pre-registered a prediction that people would rate the economic distribution as less fair and indicate greater support for redistribution when the same information is displayed in the Average Wealth condition compared to those in the Total Wealth condition.

2.2 Results. As predicted, we find that perceived fairness of the distribution was significantly lower $(b=-.79, t=-2.34, p<.05)$ and the subsequent support for redistribution was significantly greater $(b=1.40, t=3.39, p<.001)$ in the Average Wealth condition. This condition uses a "partition-invariant metric" that scales the wealth allocation by the size of the group, leading to fairness and policy judgments that are not biased by arbitrary differences in the size of the identified population groups.

\section{Study 2: Partition-Dependence}

In Study 2, we test the first hypothesis of the salient-group inequality (SGI) heuristic, that people are under-sensitive to the size of different groups in judgments of economic inequality. We find evidence in support of the hypothesis that judgments are biased according to the arbitrary partitioning of the population groups.

We note that here, as with all studies regarding Partition Dependence (i.e., Studies 2-5) which use the paradigm slightly adapted from Norton and Ariely (2011), we include the training module at the start of the study. Noting that this module had a significant effect on participant understanding of the task, we wanted to increase the reliability of participants' preferences expressed in these studies. In other words, we wanted to maximize the chances that participants were giving meaningful responses. Thus, when we document effects of Partition Dependence, we take our estimates to be a lower-bound measure of the size of the effect absent this training.

3.1 Methods and Participants. In Study 2, we recruited 165 participants from Amazon's Mechanical Turk who met pre-registered inclusion criteria $\left(44 \%\right.$ female, $\mathrm{M}_{\text {age }}=36.1, \mathrm{SD}_{\mathrm{age}}=$ 11.8). Participants were randomly assigned to construct the actual and ideal wealth distribution of the United States using one of two population partitions. In the Quintiles condition, participants used population quintiles (e.g. richest $20 \%$ of Americans, next $20 \%, \ldots$, poorest $20 \%$ ), and in the Logarithmic condition the population groups were defined as richest $1 \%$, next $4 \%$, next $15 \%$, next $30 \%$, poorest $50 \%$ (Figures $2 \mathrm{~A}$ and $2 \mathrm{~B}$ ). In each condition, participants indicated what they believed to be the current wealth distribution in the United States (Descriptive Allocation Task) as well as their opinion on how wealth ideally should be distributed (Ideal Allocation Task). Afterwards, participants answered a few demographic questions including partisanship $(0=$ Democrat, $1=$ Republican $)$, fiscal conservatism (When it comes to your attitudes on fiscal issues, how would you rate yourself on the following scale? 
1=Extremely conservative, 7=Extremely liberal), MacArthur Subjective Social Status Scale (110), and self-placement on two items from the World Values Survey:

a) $1=$ Income should be made more equal, $10=$ We need larger income differences as incentives for individual effort

b) $1=$ In the long run, hard work usually brings a better life, $10=$ Hard work doesn't generally bring success - it's more a matter of luck and connections

3.2 Results. As predicted, participants in the Logarithmic condition allocated significantly more wealth to the richest $20 \%$ in both the Ideal and Descriptive Allocation task, as compared to participants in the Quintiles condition (Table S1). Thus we find further evidence that judgments of economic inequality are partition-dependent such that people are under-sensitive to the size the of the population groups. People allocate more wealth to the richest $20 \%$ of Americans when this population is partitioned into four (versus one) group. This pattern is consistent with the SGI heuristic. 
Table S2: Study 2 effects of partitioning the population Logarithmically versus by Quintiles on descriptive and ideal wealth allocations

\begin{tabular}{|c|c|c|c|c|}
\hline & \multicolumn{4}{|c|}{ Dependent variable: } \\
\hline & \multicolumn{2}{|c|}{ Allocation to Top 20\%: Descriptive } & \multicolumn{2}{|c|}{ Allocation to Top $20 \%$ : Ideal } \\
\hline & (1) & $(2)$ & (3) & (4) \\
\hline \multirow[t]{2}{*}{ logarithmic condition } & $12.624^{* *}$ & $13.184^{*}$ & $19.594^{* * *}$ & $21.491^{* * *}$ \\
\hline & $(4.206)$ & $(5.187)$ & $(4.038)$ & $(4.594)$ \\
\hline \multirow[t]{2}{*}{ republicanism } & & 5.970 & & -1.462 \\
\hline & & $(7.328)$ & & $(6.490)$ \\
\hline \multirow[t]{2}{*}{ fiscal conservatism } & & 0.955 & & -1.835 \\
\hline & & $(1.900)$ & & $(1.683)$ \\
\hline \multirow[t]{2}{*}{ WVS: Incentivize } & & -1.746 & & -1.158 \\
\hline & & $(1.113)$ & & $(0.985)$ \\
\hline \multirow[t]{2}{*}{ WVS: Success as Luck } & & -0.115 & & 1.126 \\
\hline & & $(1.037)$ & & $(0.918)$ \\
\hline \multirow[t]{2}{*}{ MacArthur SES } & & 2.900 & & -1.423 \\
\hline & & $(1.592)$ & & $(1.410)$ \\
\hline \multirow[t]{2}{*}{ Constant } & $22.763^{*}$ & 8.589 & 4.956 & 13.412 \\
\hline & $(10.508)$ & $(18.708)$ & $(10.089)$ & $(16.569)$ \\
\hline Observations & 165 & 122 & 165 & 122 \\
\hline $\mathrm{R}^{2}$ & 0.052 & 0.106 & 0.126 & 0.195 \\
\hline Adjusted $\mathrm{R}^{2}$ & 0.047 & 0.059 & 0.121 & 0.153 \\
\hline Residual Std. Error & $26.868(\mathrm{df}=163)$ & $27.122(\mathrm{df}=115)$ & $25.797(\mathrm{df}=163)$ & $24.021(\mathrm{df}=115)$ \\
\hline F Statistic & $9.010^{* *}(\mathrm{df}=1 ; 163)$ & $2.276^{*}(\mathrm{df}=6 ; 115)$ & $23.544^{* * *}(\mathrm{df}=1 ; 163)$ & $4.652^{* * *}(\mathrm{df}=6 ; 115)$ \\
\hline
\end{tabular}

Here we report unstandardized coefficients and standard errors. Models 1 and 2 report the effects on total allocation of wealth to the richest $20 \%$ of Americans in the Descriptive Allocation Task (participants' estimates of the true distribution of wealth in the United States). Models 3 and 4 report the effects on total allocation of wealth allocated to the richest 20\% of Americans in the Ideal Allocation Task (participants report what the wealth distribution of the United States ideally should be, in their opinion).

The effects of condition hold controlling for the battery of political opinions. As can be seen, for both the Descriptive and Ideal condition, in both the controlled and uncontrolled regressions, considerably more wealth was allocated to the top $20 \%$ of Americans when they represented more population groups. 


\section{Study 3: Different Number of Groups}

In the previous study, we found a large partitioning effect when the richest $20 \%$ of the population was partitioned into three sub-groups (richest $1 \%$, next $4 \%$, next 15\%). In Study 3 , we test the generalizability of partition dependence in judgments of economic distributions using an alternative method of dividing national wealth. We wanted to ensure that the effects of partitioning were not unique to an uneven, quasi-logarithmic unpacking of the top wealth group. Thus, in Study 3, we unpacked the top wealth group into evenly spaced population groups.

4.1 Methods and Participants. We recruited 162 participants from Amazon's Mechanical Turk who met pre-registered inclusion criteria $\left(51 \%\right.$ female, $\left.\mathrm{M}_{\text {age }}=37.7, \mathrm{SD}_{\text {age }}=11.8\right)$. Following the same paradigm as in Study 2, participants completed the Descriptive and Ideal Allocation Tasks using one of two population partitions. In the $\{50-50\}$ condition, participants simply estimated how much wealth was held by the "richest $50 \%$ of Americans" and the "poorest $50 \%$ of Americans," as well as how much wealth they thought each of these groups ideally should hold. In the $\{10-10-10-10-10-50\}$ condition, the richest $50 \%$ of Americans were partitioned into 5 deciles.

4.2 Results. As predicted, people allocated significantly more wealth to the richest $50 \%$ of Americans in both the Ideal and Descriptive Allocation Task when this population group was partitioned into five deciles. 
Table S3: Study 3 effects of a 50-50 partition versus a 10-10-10-10-10-50 partition on descriptive and ideal wealth allocations

Dependent variable:

\begin{tabular}{|c|c|c|c|c|}
\hline & \multicolumn{2}{|c|}{ Allocation to Top 20\%: Descriptive } & \multicolumn{2}{|c|}{ Allocation to Top 20\%: Ideal } \\
\hline & (1) & (2) & (3) & (4) \\
\hline \multirow[t]{2}{*}{ unpacked condition } & $8.029^{* * *}$ & $10.760^{* * *}$ & $7.635^{* *}$ & $9.188^{* *}$ \\
\hline & $(1.675)$ & $(1.797)$ & $(2.304)$ & $(2.843)$ \\
\hline \multirow[t]{2}{*}{ republicanism } & & -0.419 & & -3.194 \\
\hline & & $(3.118)$ & & $(4.933)$ \\
\hline \multirow[t]{2}{*}{ fiscal conservatism } & & 0.159 & & -1.541 \\
\hline & & $(0.745)$ & & $(1.179)$ \\
\hline \multirow[t]{2}{*}{ WVS: Incentivize } & & -0.535 & & 0.993 \\
\hline & & $(0.522)$ & & $(0.826)$ \\
\hline \multirow[t]{2}{*}{ WVS: Success as Luck } & & 0.330 & & -0.146 \\
\hline & & $(0.402)$ & & $(0.636)$ \\
\hline \multirow[t]{2}{*}{ MacArthur SES } & & $-1.338^{*}$ & & 0.553 \\
\hline & & $(0.586)$ & & $(0.927)$ \\
\hline \multirow[t]{2}{*}{ Constant } & $87.801^{* * *}$ & $95.122^{* * *}$ & $64.570^{* * *}$ & $67.681^{* * *}$ \\
\hline & $(0.837)$ & $(5.528)$ & $(1.152)$ & $(8.745)$ \\
\hline Observations & 162 & 104 & 162 & 104 \\
\hline $\mathrm{R}^{2}$ & 0.126 & 0.327 & 0.064 & 0.182 \\
\hline Adjusted $\mathrm{R}^{2}$ & 0.120 & 0.285 & 0.058 & 0.132 \\
\hline Residual Std. Error & $10.607(\mathrm{df}=160)$ & $8.961(\mathrm{df}=97)$ & $14.593(\mathrm{df}=160)$ & $14.176(\mathrm{df}=97)$ \\
\hline F Statistic & $\begin{array}{c}22.976^{* * *}(\mathrm{df}=1 \\
160)\end{array}$ & $7.853^{* * *}(\mathrm{df}=6 ; 97)$ & $10.979^{* *}(\mathrm{df}=1 ; 160)$ & $3.604^{* *}(\mathrm{df}=6 ; 97)$ \\
\hline
\end{tabular}

Here we report unstandardized coefficients and standard errors. Models 1 and 2 report the effects on total allocation of wealth to the richest $20 \%$ of Americans in the Descriptive Allocation Task (participants' estimates of the true distribution of wealth in the United States). Models 3 and 4 report the effects on total allocation of wealth allocated to the richest $20 \%$ of Americans in the Ideal Allocation Task (participants report what the wealth distribution of the United States ideally should be, in their opinion).

These findings indicate that people are willing to tolerate more wealth inequality when the richest segment of the population is subdivided into more groups. Consistent with the SGI heuristic, we find a bias toward even allocation between groups without sufficient sensitivity to differences in group sizes. 


\section{Study 4: Actual Distribution Given}

In Study 4, we focused on the Ideal Allocation Task only. In Studies 2 and 3, we found that participants' estimates of the actual wealth distribution of the United States were systematically biased by the arbitrary partitioning of population groups. These inaccurate estimates of the actual wealth distribution may partially explain people's opinions about their preferred distribution. Therefore, in Study 4, we tested whether partitioning effects on preferred economic inequality hold when people have accurate information about the current distribution.

5.1 Methods and Participants. We recruited 140 participants from Amazon's Mechanical Turk who met pre-registered inclusion criteria ( $44 \%$ female, $\left.\mathrm{M}_{\mathrm{age}}=39.0, \mathrm{SD}_{\mathrm{age}}=12.9\right)$. Participants were presented with accurate information on the current wealth distribution in the United States (using a 50-50 population partition). Then, participants were randomly assigned to either a Deciles condition or Quartiles condition to indicate their ideal wealth distribution (using the same Ideal Allocation Task as in Studies 2 and 3). In the Deciles condition, the population was partitioned into six groups (richest $10 \%$, next $10 \%$ next $10 \%$, next $10 \%$, next $10 \%$, poorest $50 \%$ ). In the Quartiles condition the population was partitioned into three groups (richest 25\%, next $25 \%$, poorest $50 \%$ ).

5.2 Results. Despite having accurate information regarding the way wealth is currently allocated, people's ideal constructions of wealth distributions would remain partition dependent. This is, in fact, what we find. Controlling for the political covariates described in Study 2 and Study 3, we find that participants in the Deciles condition allocated $72 \%$ of national wealth to the top half of the distribution whereas participants in the Quartiles condition allocated just $64 \%(b=7.99$, $\mathrm{t}=2.78, \mathrm{p}<0.01)$. This result is directionally similar to the uncontrolled regression not accounting for political differences, but this uncontrolled regression is only marginally significant $(b=5.31, t=1.73, p=0.086)$.

\section{Study 5: Partition-Invariant Metrics for Displaying Economic Distributions}

The previous studies demonstrate that judgments of economic inequality are under-sensitive to differences in the size of population groups presented. This results in a systematic bias when economic distributions are presented with population groups of unequal size, which is typical in the popular press (e.g., comparing the richest 1\% of Americans versus the bottom 99\%).

Journalists and policymakers use these types of comparisons to highlight the extent of the wealth gap, but doing so leads readers and voters to form biased impressions-systemically underestimating economic inequality and the need for policies to redistribute wealth. In Study 5, we tested a method to reduce this bias using metrics of displaying economic inequality that are partition-invariant. 
6.1 Methods and Participants. We recruited 679 participants from Amazon's Mechanical Turk who met pre-registered inclusion criteria $\left(56 \%\right.$ female, $\left.\mathrm{M}_{\text {age }}=37.7, \mathrm{SD}_{\text {age }}=12.0\right)$. Participants were randomly assigned to one of four experimental conditions in a 2 (partitioning: quintiles versus logarithmic) x 2 (units: total versus average wealth) experimental design. The first experimental factor varied whether participants were presented with population groups partitioned either into quintiles (richest $20 \%$, next $20 \%, \ldots$, poorest $20 \%$ ) or quasilogarithmically (richest $1 \%$, next $4 \%$, next $5 \%$, next $10 \%$, next $20 \%$, ., poorest $20 \%$ ). The second experimental factor varied the metric used to define the amount of wealth held by each population group. Half of participants were presented with the distribution using a Total Wealth metric (i.e., displaying the percentage of total wealth held by a given population group), and the other half of participants were presented with an Average Wealth metric (i.e., the average wealth held per percentile; percent-per-percentile). The latter metric is partition invariant since it is scaled by the number of individuals in a group.

Participants observed the wealth distribution and then responded to three questions asking their opinions on the fairness of the distribution and three questions asking about the extent to which they would support redistributing wealth from richer to poorer citizens. The order of the three questions within each block was randomized. Participants were shown a given distribution and asked to place themselves on the following scales:

- Fairnessa: 1=Ideally, rich Americans would own much more wealth, 6=Ideally, no change from this distribution, 11=Ideally, poor Americans would own much more wealth

- Fairnessb: 1=Ideally, the wealth distribution should be much more unequal, $6=$ Ideally, no change from this distribution, 11=Ideally, the wealth distribution should be much more equal

- Fairness ${ }_{c}$ : $1=$ This distribution is not at all unfair, $7=$ This distribution is extremely unfair

- Policy Support ${ }_{\mathrm{a}}$ : 1=Given this distribution, I would strongly oppose a government policy that redistributes more money to the poor, $6=$ Neither oppose nor support, $11=$ Given this distribution, I would strongly support a government policy that redistributes more money to the poor

- Policy Supportb: 1= Given this distribution, I think the government should significantly decrease taxes on the rich, $6=$ Taxes on the rich should stay the same as they are today, $11=$ Given this distribution, I think the government should significantly increase taxes on the rich

- Policy Supportc: 1=Given this distribution, I think the government should significantly decrease services that benefit the poor, $6=$ Government services that benefit the poor should stay the same as they are today, 11=Given this distribution, I think the government should significantly increase services that benefit the poor

From these six questions we constructed composite measures of fairness $(\alpha=0.70)$ and support for redistribution $(\alpha=88)$.

We pre-registered a prediction that the partition dependence bias would we be diminished (i.e. a smaller difference between the alternative population partitions in terms of reported fairness and support for redistributions) when wealth is expressed using a partition-invariant metric (i.e., average wealth). 


\section{HEURISTICS AND BIASES IN EVALUATIONS OF ECONOMIC INEQUALITY}

6.2 Results. As predicted, using the partition-invariant metric of "percent per percentile" (analogous to average wealth) reduced the difference between partition effects on fairness judgments and support for redistributional policy. We observe a significant interaction effect between our two treatment factors such that partitioning effects on fairness $(b=1.49, t=3.56$, $\mathrm{p}<.001)$ and support for redistribution $(\mathrm{b}=1.00, \mathrm{t}=2.09, \mathrm{p}<.05)$ are diminished when wealth is displayed using a partition-invariant metric (Figure S2 and S3).

Figure S2. Study 5 effects of metric and partitioning on judgments of unfairness Interaction Between Metrics and Partitioning rated unfairness

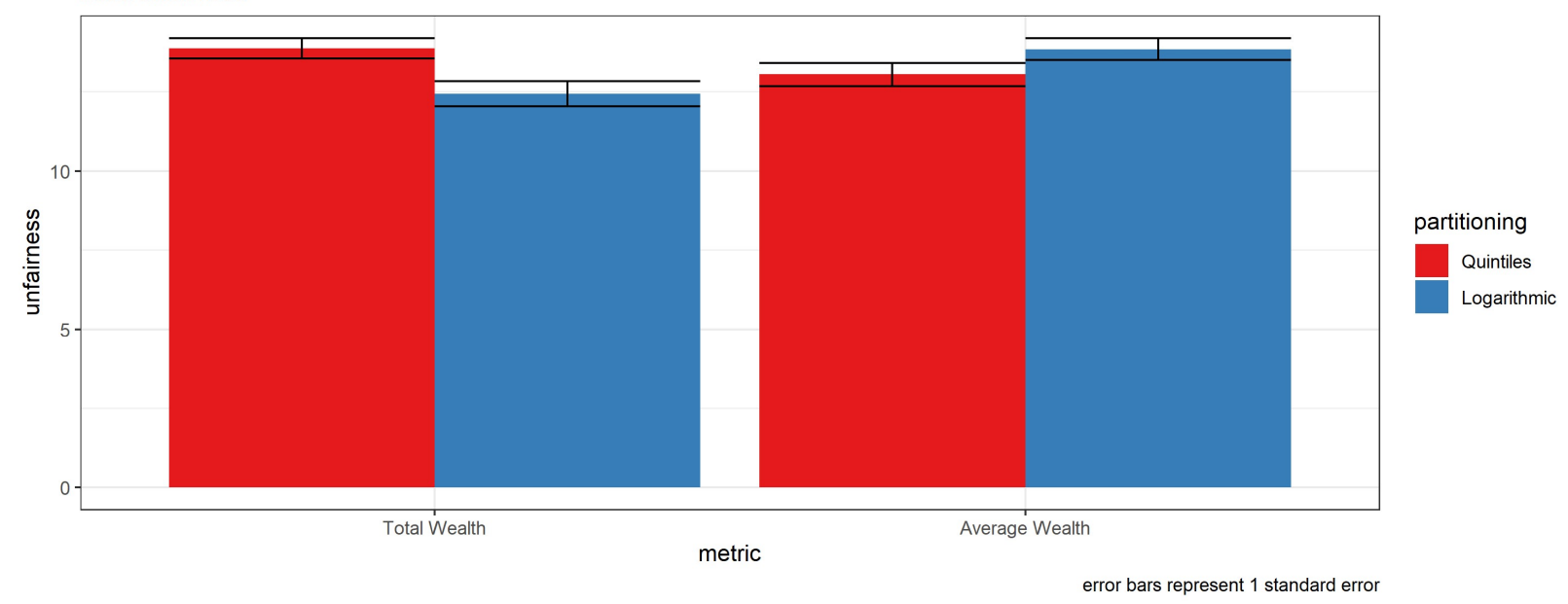

Note: Displaying means and standard error bars for treatment effects on judgments of unfairness.

Figure S3. Study 5 effects of metric and partitioning on support for redistribution Interaction Between Metrics and Partitioning support for redistributional policies

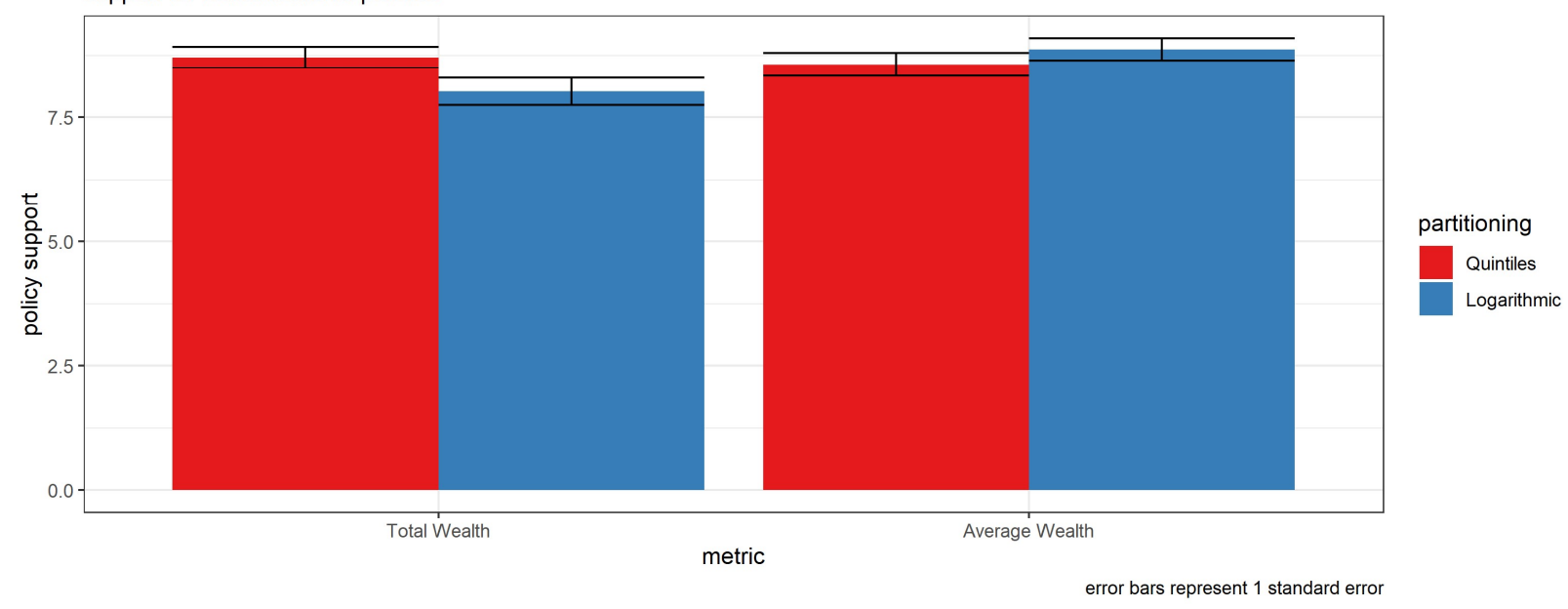

Note: Figure S3 displays means and standard error bars for treatment effects on support for redistribution

Because the reliability of the fairness index was on the lower end of acceptability, we separately regressed each of the three measures in both a controlled and uncontrolled regression (as described above). In all cases, the results were substantively unchanged: The effect of 


\section{HEURISTICS AND BIASES IN EVALUATIONS OF ECONOMIC INEQUALITY}

partitioning was significantly smaller when the distribution was expressed using an Average Wealth metric.

\section{Study 6: Middle Neglect}

In Study 6, we test the second prediction of the SGI heuristic: judgments of inequality underweight wealth held by the middle of the economic distribution relative to the extremes. We posit that people focus on a comparison between the most salient groups - the richest and poorest population segments - and therefore judgments are relatively insensitive to changes in the middle of the distribution.

7.1 Methods and Participants. We recruited 197 participants from Amazon's Mechanical Turk who met pre-registered inclusion criteria $\left(41 \%\right.$ female, $\left.\mathrm{M}_{\mathrm{age}}=34.6, \mathrm{SD}_{\mathrm{age}}=11.4\right)$. Participants were asked to make a series of judgments about the economic distribution of eight anonymous Western, democratic countries. Each economic distribution displayed the average annual income of three population segments: the richest quintile of society, the middle quintile, and the poorest quintile. We varied the average income for each population segment to be either relatively low or high. Our goal was to measure how independent changes to the income held by each population segment influenced judgments of fairness and support for redistribution. The low income-level for each population segment is roughly equal to the actual average annual income for the richest, middle, and poorest quintiles of the United States population as of 2020. The high income-level was defined by simply doubling that of the low level. Specifically, we varied the economic distributions such that the richest quintile of society was described as having an average annual income of $\$ 220,000$ or $\$ 440,000$; the middle quintile was described as having an average income of $\$ 60,000$ or $\$ 120,000$; and the poorest quintile was described as earning and average of $\$ 14,000$ or $\$ 28,000$ (Table S4). Participants observed all combinations of income levels in a random order, which yielded a total of eight hypothetical economic distributions (i.e. two income levels for three population segments in a $2^{3}$ within-subjects design). Participants were asked to assume that each distribution represented a Western, democratic country that was roughly equal in terms of population size, demographics, and total national wealth. While observing each distribution sequentially, participants rated the extent to which they thought each distribution was fair $(-5=$ completely unfair, $+5=$ completely fair) as well as their support for a government policy to redistribute wealth $(-5=$ strongly oppose, $+5=$ strongly support $)$.

Table S4. Study 6 stimuli included eight hypothetical income distributions using every combination of low and high income-levels for each population segment

\begin{tabular}{|l|c|c|}
\hline Population segment & $\begin{array}{c}\text { Average Income: } \\
\text { Low Level }\end{array}$ & $\begin{array}{c}\text { Average Income: } \\
\text { High Level }\end{array}$ \\
\hline Richest 20\% of households & $\$ 220,000$ & $\$ 440,000$ \\
\hline Middle 20\% of households & $\$ 60,000$ & $\$ 120,000$ \\
\hline Poorest 20\% of households & $\$ 14,000$ & $\$ 28,000$ \\
\hline
\end{tabular}




\section{HEURISTICS AND BIASES IN EVALUATIONS OF ECONOMIC INEQUALITY}

After rating all eight combinations of average incomes, participants responded to a series of items asking their opinions on economic inequality. Participants rated the extent to which they agreed or disagreed with the following statements $(-7=$ completely disagree, $0=$ neither agree nor disagree, $7=$ completely agree): "We ought to make sure that the POOREST members of society are doing as well as they can"; "We ought to build as strong, robust and wealthy of a MIDDLE class as possible"; and "We ought to make sure that it is possible to become EXTREMELY WEALTHY to incentivize people." Lastly, participants completed the same set of questions on political attitudes as in previous studies.

7.2 Results. We created three indicator variables corresponding to whether participants were evaluating the low or high average income for each population segment (i.e., $\$ 220,000$ average income versus $\$ 440,000$ for the rich), clustering standard errors at the person-level. As predicted, doubling the average incomes of the richest and poorest population segments significantly predicted fairness ratings, whereas we observe no significant association between fairness ratings and the average income of the middle population segment (Table S5). Doubling the income of the poorest population segment led participants to rate economic distributions as significantly more fair. Doubling the income of the richest population segment led participants to rate economic distributions significantly less fair. Doubling the income of the middle population segment had no reliable effect on fairness ratings, however. This pattern of results is consistent with the SGI heuristic.

Table S5. Study 7 regression results predicting fairness ratings.

\begin{tabular}{lcccc}
\hline & \multicolumn{5}{c}{ Fairness Ratings } \\
& beta & se & t-val & p \\
\hline intercept & 4.717 & 0.214 & 22.088 & $0.000^{* * *}$ \\
doubling inc. of poor & 1.199 & 0.125 & 9.613 & $0.000^{* * *}$ \\
doubling inc. of middle & 0.128 & 0.076 & 1.676 & 0.094 \\
doubling inc. of rich & -0.730 & 0.101 & -7.257 & $0.000^{* * *}$
\end{tabular}

Notes: reporting unstandardized coefficients testing the effect of doubling the average income of the richest, middle, and poorest quintile on perceived fairness.

We find the same pattern of results when we control for participants' opinions on economic inequality (Table S6). As expected, concern for the wellbeing of the poor has a main effect on fairness ratings. Furthermore, the effect of doubling the average income of the poor depends on people's stated concern for the poor and, similarly, doubling the average income of the rich 


\section{HEURISTICS AND BIASES IN EVALUATIONS OF ECONOMIC INEQUALITY}

depends on concern for the rich. In contrast, we observe no interaction effect between doubling the average income of the middle class and stated concern for the middle class. This pattern of results suggests that people may not neglect the middle of economic distributions for principled reasons, but rather due the way in which people simplify information about economic distributions using the SGI heuristic.

Table S6. Study 6 regression results predicting fairness rating controlling for opinions on economic inequality.

\begin{tabular}{|c|c|c|c|c|}
\hline & \multicolumn{4}{|c|}{ Fairness Ratings: Interactions with Concern } \\
\hline & beta & se & t-val & $\mathbf{p}$ \\
\hline intercept & 8.158 & 0.994 & 8.208 & $0.000 * * *$ \\
\hline doubling inc. of poor & -0.802 & 0.364 & -2.205 & $0.027^{*}$ \\
\hline concern for the poor & -0.359 & 0.072 & -5.018 & $0.000 * * *$ \\
\hline doubling inc. of middle & -0.190 & 0.287 & -0.663 & 0.507 \\
\hline concern for the middle & 0.028 & 0.073 & 0.378 & 0.705 \\
\hline doubling inc. of rich & -1.366 & 0.194 & -7.035 & $0.000 * * *$ \\
\hline concern for rich & 0.082 & 0.046 & 1.801 & 0.072 \\
\hline doubling poor : concern poor & 0.161 & 0.032 & 5.014 & $0.000 * * *$ \\
\hline doubling mid : concern mid & 0.026 & 0.023 & 1.118 & 0.264 \\
\hline doubling rich : concern rich & 0.076 & 0.021 & 3.589 & $0.000 * * *$ \\
\hline
\end{tabular}

Notes: reporting unstandardized coefficients testing the effect of doubling the average income of the richest, middle, and poorest quintile on perceived fairness.

We do not observe the same pattern of results with respect to support for redistribution (Tables S7 and S8). Only the income of richest segment of the population significantly predicts support for redistribution. 
HEURISTICS AND BIASES IN EVALUATIONS OF ECONOMIC INEQUALITY

Table S7. Study regression results predicting support for redistribution.

\begin{tabular}{lllll}
\hline & \multicolumn{5}{c}{ Support for Redistribution } \\
\hline & beta & se & t-val & p \\
\hline intercept & 7.846 & 0.262 & 29.902 & $0.000^{* * *}$ \\
doubling inc. of poor & -0.246 & 0.138 & -1.784 & 0.074 \\
doubling inc. of middle & -0.091 & 0.069 & -1.333 & 0.182 \\
doubling inc. of rich & 0.376 & 0.084 & 4.446 & $0.000^{* * *}$
\end{tabular}

Notes: reporting unstandardized coefficients testing the effect of doubling the average income of the richest, middle, and poorest quintile on support for redistribution. 
Table S8. Study regression results predicting support for redistribution controlling for opinions on economic inequality: Interactions with Concern.

\section{Support for Redistribution}

\begin{tabular}{|c|c|c|c|c|}
\hline & beta & se & t-val & $\mathbf{p}$ \\
\hline intercept & 2.230 & 1.087 & 2.052 & $0.040 *$ \\
\hline doubling inc. of poor & 0.060 & 0.480 & 0.126 & 0.900 \\
\hline concern for the poor & 0.403 & 0.084 & 4.822 & $0.000 * * *$ \\
\hline doubling inc. of middle & 0.046 & 0.225 & 0.204 & 0.838 \\
\hline concern for the middle & 0.169 & 0.087 & 1.951 & 0.051 \\
\hline doubling inc. of rich & 0.459 & 0.157 & 2.915 & $0.004 * *$ \\
\hline concern for wealth growth & -0.173 & 0.053 & -3.242 & $0.001 * *$ \\
\hline doubling poor : concern poor & -0.025 & 0.041 & -0.603 & 0.547 \\
\hline doubling mid : concern mid & -0.011 & 0.019 & -0.589 & 0.556 \\
\hline doubling rich : concern rich & -0.010 & 0.017 & -0.587 & 0.557 \\
\hline
\end{tabular}

\section{Study 7: Thought-Elicitation Procedure to Explore Middle Neglect}

Study 7 further examines "middle neglect" using a thought-elicitation procedure adapted from Query Theory (Johnson, Häubl, and Keinan, 2007). This method allowed us to investigate which information commands people's attention when evaluating economic distributions.

8.1 Methods and Participants. In Study 7, we recruited 269 participants from Amazon's Mechanical Turk who met pre-registered inclusion criteria $\left(53 \%\right.$ female, $\mathrm{M}_{\mathrm{age}}=38.3, \mathrm{SD}_{\mathrm{age}}=$ 12.0). Participants were asked to list the thoughts that occurred to them while observing the economic distributions for an anonymous country. To ensure that our results were not being driven by the particularities of a given distribution or the way it was presented, participants were randomly assigned to observe one of six possible distributions corresponding to a 2 (distribution: 


\section{HEURISTICS AND BIASES IN EVALUATIONS OF ECONOMIC INEQUALITY}

highly unequal versus highly equal) x 3 (presentation: table, pie chart, bar chart) betweensubjects design. Participants evaluated the economic distribution on fairness and considered their support for redistribution, as in previous studies. Next, participants listed each of the thoughts that occurred to them as they made these evaluations. Participants could list up to seven thoughts as open-ended text (number of thoughts listed: $\mathrm{M}_{\text {thoughts }}=3.2, \mathrm{SD}_{\text {thoughts }}=1.4$ ). Lastly, participants self-coded each of their listed thoughts into one of the following seven categories:

1. I focused on how much of the total wealth was concentrated at the TOP of the distribution

2. I focused on how much of the total wealth was at the BOTTOM of the distribution

3. I focused on the DIFFERENCE between the amount of wealth at the TOP vs the BOTTOM of the distribution

4. I focused on the RATIO of wealth at TOP to wealth at the BOTTOM of the distribution

5. I focused on how much of the total wealth was held by the MIDDLE of the distribution

6. I focused on how much the distribution differed from total equality across groups

7. Other

If participants selected "other," they were asked to create their own label. We were primarily interested in the extent to which people focused on each part of the distribution.

8.2 Results. Using thought-elicitation data, we observed the extent to which people focused on each part of the distribution when evaluating an economic distribution. Participants focused on the top of the distribution, the bottom of the distribution, and a comparison of the top and bottom. In contrast, participants devoted relatively little attention to the middle of the distribution Figures S4 and S5). "Wealth held by the middle of the distribution" was the least commonly mentioned thought (52 instances).

Figure S4. Self-categorized areas of focus when evaluating of an economic distribution.

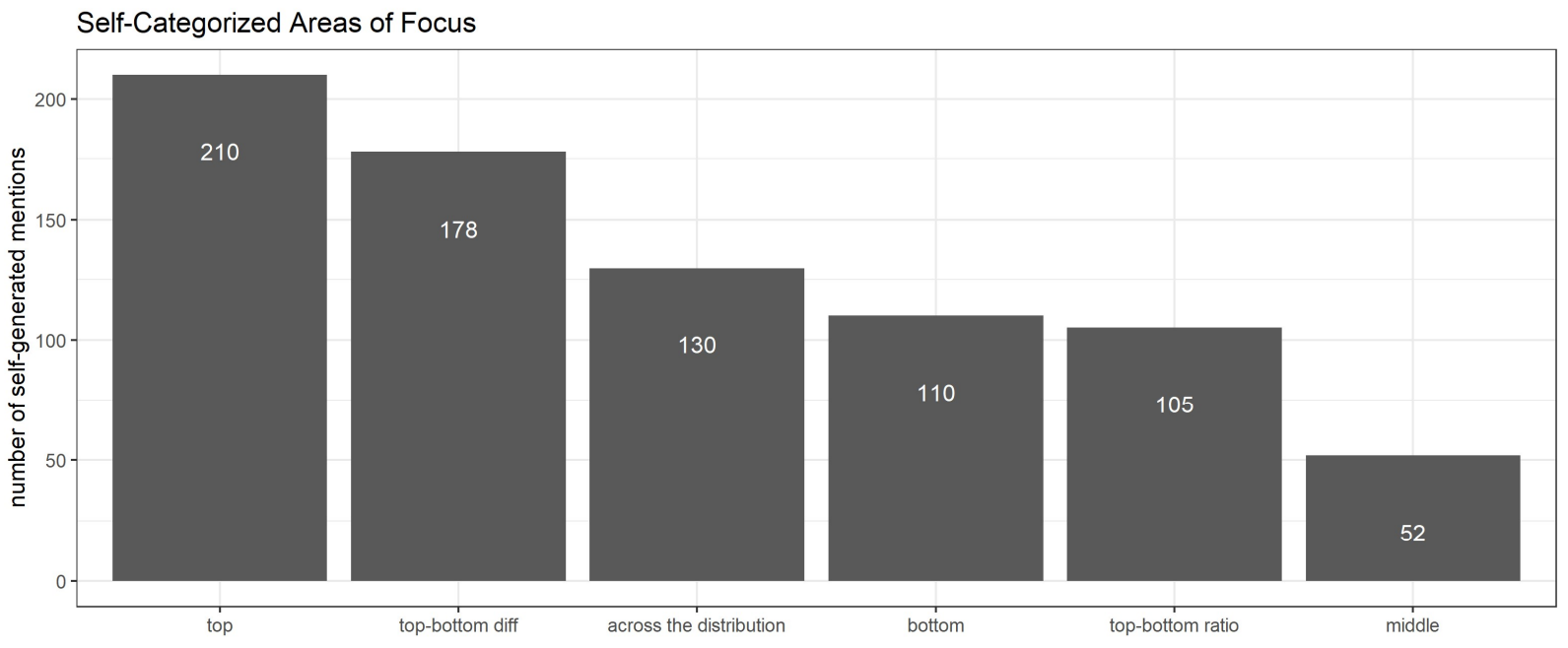


Figure S5. Self-categorized areas of focus when evaluating of an economic distribution, results by condition.

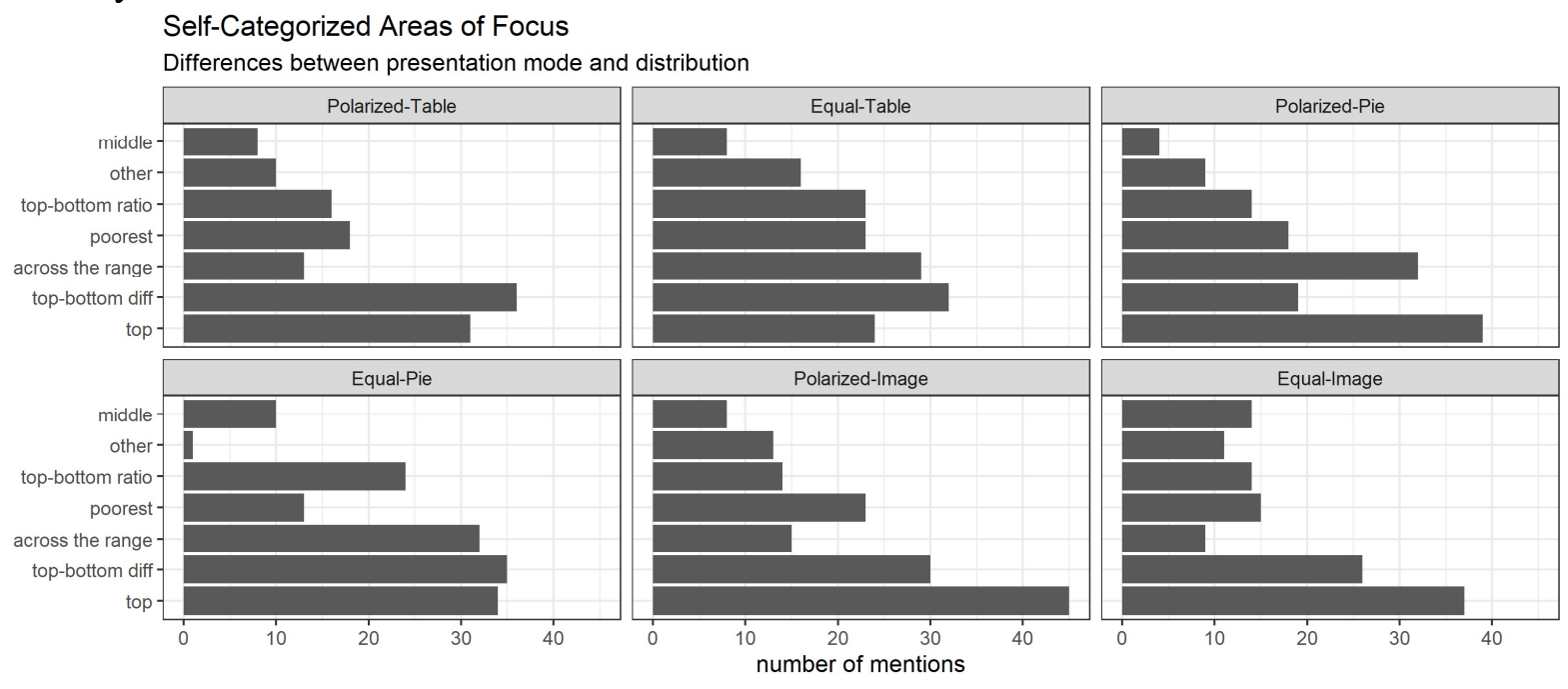

We found that people pay little attention to the middle of the economic distribution. We find further that this is true of both more and less extremely unequal allocations, and true across presentation formats. These results are consistent with the claim that disregard of the middle class is not ideologically motivated but rather a "cognitive blind spot" such that people tend to over-weight information about the extremes of a distribution relative to the middle.

\section{Study 8: Mitigating Middle Neglect with Visual Displays}

In Study 8, we tested a method to reduce middle neglect using visual displays of economic distributions, which facilitate a more holistic processing of information.

9.1 Methods and Participants. In Study 8, we recruited 393 participants from Amazon's Mechanical Turk who met pre-registered inclusion criteria $\left(50 \%\right.$ female, $\mathrm{M}_{\text {age }}=39.2, \mathrm{SD}_{\text {age }}=$ 11.6). Participants observed a pair of wealth distributions for anonymous countries with the populations partitioned into quartiles. One of these distributions had a larger gap between the richest and the poorest quartiles but a smaller gap between intermediate quartiles ("Middle Fair"). The other distribution had a smaller gap between the richest and poorest quartiles but a larger gap between the intermediate quartiles ("Top-Bottom Fair"). Participants were randomly assigned to observe the distributions presented either as tables or as bar graphs. While observing the pair of distributions, participants made a binary choice: "which of these two distributions seems to you to be more fair?" 


\section{HEURISTICS AND BIASES IN EVALUATIONS OF ECONOMIC INEQUALITY}

We pre-registered a prediction that participants would be more likely to choose the Middle Fair distribution when these distributions were displayed as bar graphs since a visual display facilitated an evaluation of the full distribution.

9.2 Results. As predicted, participants were more likely to choose the Middle Fair distribution as the "more fair" alternative when they viewed the pair of distribution as bar graphs rather than as tables. These results are robust controlling for socioeconomic status, fiscal conservatism, and opinions on economic inequality (Table S8).

Table S9. Study 8 logistic regressions results predicting choices among distributions

Dependent variable:

likelihood of choosing the Middle Fair distribution

(1)

\begin{tabular}{|c|c|c|c|c|}
\hline graphical display & $\begin{array}{l}1.031^{* * *} \\
(0.263)\end{array}$ & $\begin{array}{l}1.078^{* * *} \\
(0.266)\end{array}$ & $\begin{array}{l}1.136^{* * *} \\
(0.274)\end{array}$ & $\begin{array}{l}1.125^{* * *} \\
(0.274)\end{array}$ \\
\hline MacArthur SES & & $\begin{array}{l}0.164^{*} \\
(0.080)\end{array}$ & $\begin{array}{c}0.107 \\
(0.085)\end{array}$ & $\begin{array}{c}0.069 \\
(0.090)\end{array}$ \\
\hline fiscal conservatism & & & $\begin{array}{l}0.340^{* * *} \\
(0.077)\end{array}$ & $\begin{array}{l}0.257^{* *} \\
(0.099)\end{array}$ \\
\hline WVS: Incentivize & & & & $\begin{array}{c}0.058 \\
(0.064)\end{array}$ \\
\hline WVS: Success as Luck & & & & $\begin{array}{l}-0.049 \\
(0.060)\end{array}$ \\
\hline Constant & $\begin{array}{c}-1.385^{* * *} \\
(0.131)\end{array}$ & $\begin{array}{c}-2.166^{* * *} \\
(0.411)\end{array}$ & $\begin{array}{c}-3.302^{* * *} \\
(0.521)\end{array}$ & $\begin{array}{c}-2.785^{* * *} \\
(0.761)\end{array}$ \\
\hline Observations & 393 & 393 & 393 & 393 \\
\hline Log Likelihood & -194.402 & -192.250 & -181.642 & -180.736 \\
\hline Akaike Inf. Crit. & 392.803 & 390.501 & 371.284 & 373.471 \\
\hline
\end{tabular}

Here we report unstandardized coefficients along with standard errors.

These results are consistent with the hypothesis that people afford greater weight to the middle of economic distributions when information is displayed graphically rather than tabularly. When people view economic distributions tabularly, they have a harder time representing the full set of information and are instead more likely to rely on the SGI heuristic. People wishing to convey 


\section{HEURISTICS AND BIASES IN EVALUATIONS OF ECONOMIC INEQUALITY}

information about inequality would do well to present this information graphically thereby facilitating a more even-handed evaluation of information across the distribution.

\section{Study 10: Auditing Popular Representations of Inequality}

We sought to measure how well the popular press represents economic inequality. Specifically, we wanted to audit the frequency with which newspapers present information about economic inequality in a way that facilitates unbiased interpretation of the data. Thus, a trained team of Research Assistants (RAs) read every relevant article in the year 2020 from a set of newspapers, coding them according to various features.

\subsection{Methods}

We first constructed a database of every relevant article from the year 2020 printed in one of the eight most popular newspapers (by circulation ${ }^{42}$ ): New York Times, USA Today, Tampa Bay Times, Washington Post, Wall Street Journal, Los Angeles Times, Chicago Tribune, Houston Chronicle. We searched Factiva, an online database including those periodicals, and collected every article title containing one of the following search terms:

- Income inequality

- Wealth inequality

- Income equality

- Wealth equality

- Income distribution

- Wealth distribution

- Income allocation

- Wealth allocation

- Inequality

This returned 3128 unique articles. After several rounds of training, a team of RAs read through the results of this query and selected all articles relevant for our purposes - those with a visual, tabular, or verbal representation of how money is distributed among people. This resulted in a collection of 58 articles with visual displays of economic distributions and 335 articles with verbal descriptions of economic distributions. Of these, RAs then evaluated each distribution representation along the following dimensions:

- Visual
- Graph type
- Time series
- Unequal bin sizes (i.e., comparing richest $10 \%$ versus rest of country)
- Number of bins represented
$\circ$ Whether population categories are exclusive

${ }^{42}$ https://www.agilitypr.com/resources/top-media-outlets/top-15-daily-american-newspapers/ 
- Whether population categories are exhaustive

○ $\mathrm{X}$-axis \& Y-axis metrics

- Verbal

- Unequal bin sizes

- Scaled (e.g., average income) or aggregate (e.g., total share of wealth held) metric

- Explicit mention of intermediate income group

One lead RA, who helped to develop this coding scheme, arbitrated any disagreement or confusion about the way that an article ought to be evaluated along one of the dimensions.

\subsection{Results}

Table S10 displays the results of this audit.

Table S10. Results of the audit of popular representations of economic distributions.

$\begin{array}{rr}\text { Visual Depictions (58 graphs) } & \\ \text { Unequal Bin Sizes } & 77 \% \\ \text { Verbal Depictions (335 graphs) } & \\ \text { Unequal Bin Sizes } & 94 \% \\ \text { Aggregate Metric } & 62 \% \\ \text { Unequal Bins with Aggregate } & 63 \% \\ \text { Metric } & \\ \text { Explicit Mention of Extremes, } & 57 \% \\ \text { Not Middle } & \end{array}$

As can be seen, the majority of articles represent the distribution of money in ways that enable biased interpretation. It is no surprise, then, that so many people have such inaccurate views of inequality: Indeed, the most common ways of encountering information about inequality are opposed to even-handed evaluation of the data. 